\title{
Review of the Eumerus tricolor species group (Diptera: Syrphidae) in Iran, with description of six new species
}

\author{
Ebrahim GILASIAN ${ }^{1, *}$, Jeroen van STEENIS $^{2} \&$ Mehrdad PARCHAMI-ARAGHI $^{3}$ \\ ${ }^{1,3}$ Insect Taxonomy Research Department, Iranian Research Institute of Plant Protection (IRIPP), \\ Agricultural Research, Education and Extension Organization (AREEO), Tehran, 19395-1454, Iran. \\ ${ }^{2}$ Research Associate NBC-Naturalis, Leiden. \% Hof der Toekomst 48, \\ 3823 HX Amersfoort, The Netherlands. \\ *Corresponding author: ebrahimgilasian@gmail.com; gilasian@iripp.ir \\ 2Email: jvansteenis@syrphidaeintrees.com \\ ${ }^{3}$ Email: maraghi20@yahoo.ca

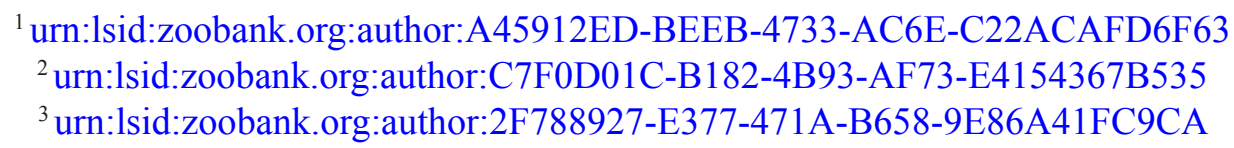

\begin{abstract}
The species of the Eumerus tricolor species group in Iran are reviewed. Six species new to science are described from Iran, i.e., Eumerus atricolorus Gilasian \& van Steenis sp. nov., E. brevipilosus Gilasian \& van Steenis sp. nov., E. chekabicus Gilasian \& van Steenis sp. nov., E. ovoformus Gilasian \& van Steenis sp. nov., E. pilosipedes Gilasian \& van Steenis sp. nov. and E. vallicolus Gilasian \& van Steenis sp. nov. Three species, E. hissaricus Stackelberg, 1949, E. longitarsis Peck, 1979 and E. richteri Stackelberg, 1960, are newly recorded from Iran. Photographs of the species as well as illustrations of the male genitalia of the new species and closely related species are provided. An identification key to the males of the Iranian Eumerus tricolor species group is presented. A row of long posterodorsal setae on the wing vein costa basally is presented and argued as a new diagnostic morphological character for the entire Eumerus tricolor species group.
\end{abstract}

Keywords. Hoverflies, Merodontini, new records, Palaearctic, taxonomy.

Gilasian E., Steenis J. van \& Parchami-Araghi M. 2020. Review of the Eumerus tricolor species group (Diptera: Syrphidae) in Iran, with description of six new species. European Journal of Taxonomy 722: 106-152. https://doi.org/10.5852/ejt.2020.722.1139

\section{Introduction}

The genus Eumerus Meigen, 1822 (Syrphidae: Merodontini) with more than 300 described species is one of the most diverse genera of hoverflies, which largely inhabit arid and semi-arid regions of the world (Grković et al. 2019a; Mutin 2019). Adults of Eumerus are distinguishable among syrphid genera by the recessive, biangulate wing vein $M_{1}$ in addition to their usually black or blackish-red aspect with greyish pollinosity of abdominal terga. They are fast flying with a visiting preference for flowers belonging 
to different families such as Apiaceae, Euphorbiaceae, Asteraceae and Ranunculaceae (Grković et al. 2019a). Despite Eumerus being primarily considered an Old World genus, with more than 170 and 70 species in the Palaearctic and Afrotropical regions respectively, the genus has been introduced to the Western Hemisphere in the wake of international trade with plant bulbs (Grković et al. 2015, 2019a, 2019b; van Steenis et al. 2017; Mutin 2019).

Eumerus species usually achieve pest status when their larvae are found in commercial plant tissues. The larvae of a number of species, in their early stages, are able to employ their special mouthpart structures to feed on semi-liquid food substances, which are mostly abundant in the decaying stages of plant organs. The Eumerus larval infestation of roots, fruits, bulbs and stems of different plant families, including Liliaceae, Amerillaceae and Orobanchaceae, sometimes constitute serious damage to ornamental and crop plants. So, with feeding on a wide range of plant tissues and taxa, including commercial species, Eumerus is considered a polyphagous genus (Ricarte et al.2008, 2017; Grković et al. 2015; Mutin 2016, 2019; van Steenis et al. 2017; Souba-Dols et al. 2020).

The Eumerus tricolor species group can be identified by the combination of the following characters: basoflagellomere radially furrowed, apico-laterally with clearly demarcated, ellipsoidal fossa; katepisternum ventrally, medially and dorsally pilose; wing vein costa with a row of long posterodorsal setae basally; terga often more or less red coloured; anterior surstylus lobe undeveloped.

There is little literature on the Iranian fauna of Eumerus as it is partly compiled through the identification of eight species of the Eumerus tricolor group, of which four species had originally been described from Iran (Peck 1988; Barkalov \& Gharali 2004; Gilasian \& Barkalov 2004; Kamangar et al. 2004; Bahirai et al. 2014).

The Palaearctic species of the genus Eumerus were reviewed by Stackelberg (1961), whose identification key to males and females included the new species E. persarum Stackelberg, 1961 from Iran. Later, Peck $(1966,1971)$ described further species of the Eumerus tricolor group and incorporated them in Stackelberg's identification key. Grković et al. (2017) have recently studied the European members of this species group in Southeastern Europe and improved its taxonomic status and added the new species E. rubrum Grković \& Vujić, 2017. The Spanish fauna of oak dehesa hoverflies was investigated by Ricarte et al. (2018), resulting in the respective description and redescription of $E$. azabense Ricarte \& Marcos-García, 2018 and E. niveitibia Becker, 1921, as well as the confirmation of the monophyly of the Eumerus tricolor group. Grković et al. (2015) also revised the Eumerus species in eastern Mediterranean islands and described a new species from the islands of Lesvos, Samos and Rhodes in Greece, as E. aurofinis Grković, Vujić \& Radenković, 2015. Grković et al. (2019a) chose the name "binominatus" to include the long-legged species for a newly defined subgroup of the Eumerus tricolor group and provided a key to all known European species of the Eumerus binominatus subgroup.

This study is part of a project on the taxonomy of the genus Eumerus in Iran and aims to improve existing knowledge on this genus in the West Palaearctic region.

\section{Material and methods}

The material of the Eumerus tricolor species group was mostly collected from areas located in southern, northeastern and central Iran (Figs 1-2). The depositories for the studied material are as follows:

HMIM = Hayk Mirzayans Insect Museum, Insect Taxonomy Research Department, Iranian Research Institute of Plant Protection, Tehran, Iran

JSA $=$ private collection of Jeroen van Steenis, Amersfoort, the Netherlands

ZISP $=$ Zoological Museum, Russian Academy of Sciences, St. Petersburg, Russia 
ZMHB = Museum of Natural History, Leibniz-Institute for Research on Evolution and Biodiversity, Berlin, Germany

$\mathrm{ZMSU}=$ Zoological Museum of the Moscow State University, Moscow, Russia

The specimens were captured by Malaise traps or sweeping nets. To prepare some specimens from ethanol, we followed the AXA method proposed by van Achterberg (2009) to avoid shrinkage of the specimens, before pinning them. An Olympus BH-2 microscope, equipped with a drawing tube, was used for preparing the illustrations of the male genitalia. Inked drawings were edited using Adobe
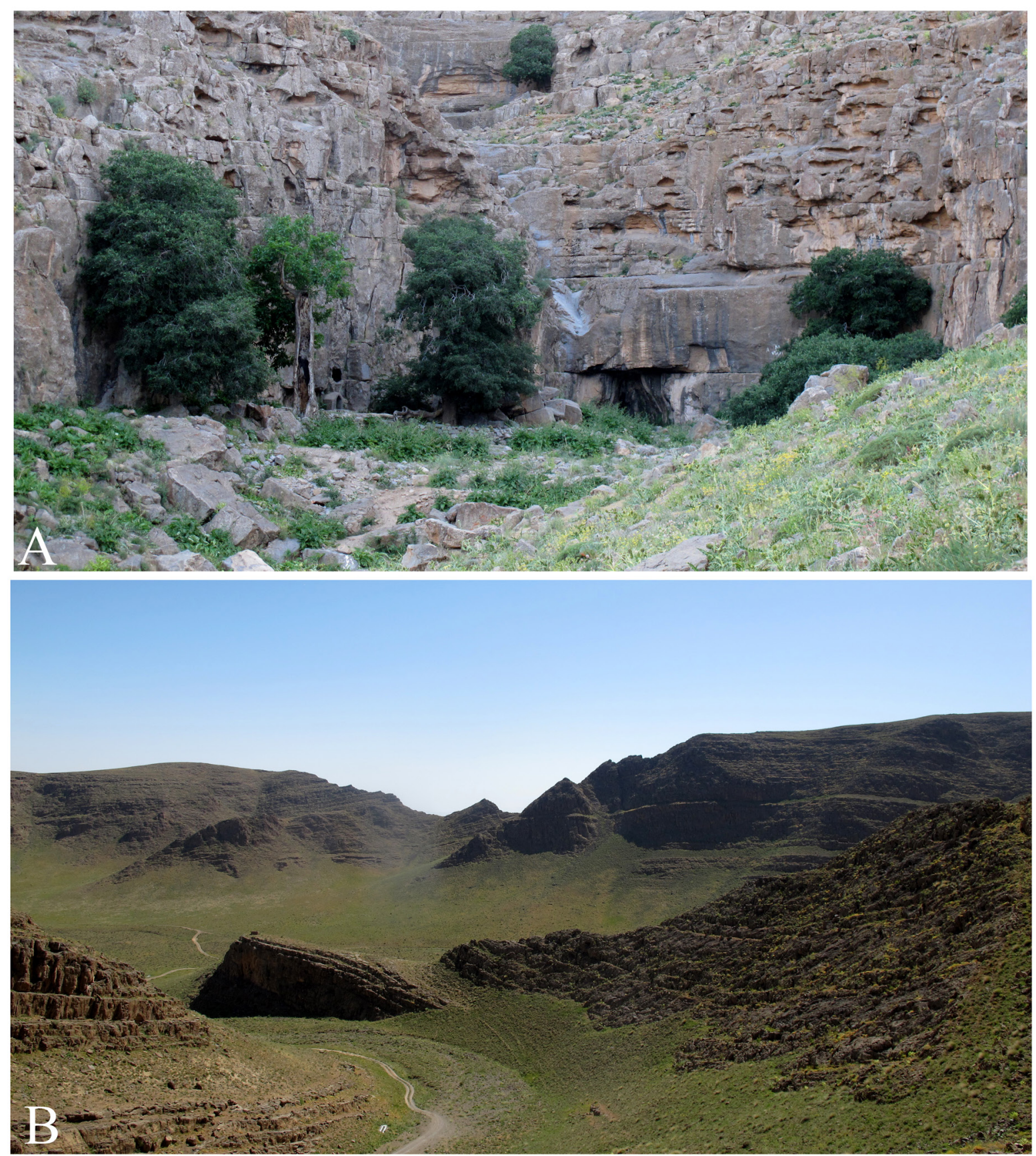

Fig. 1. A-B. Chekab Valley, Haftad Qolleh Protected Area, Markazi province, Iran. 
Photoshop CS2. To study the male genitalia of the specimens, we gently removed the whole abdomen and heated it at $85^{\circ} \mathrm{C}$ in a $10 \% \mathrm{KOH}$ solution for $15-20$ minutes. The abdomen was later washed in distilled water and briefly put in glacial acetic acid to neutralize the base. Then, the genitalia were detached from the abdomen and placed in a microvial containing glycerin as a preservative, and pinned below the source specimen.

The photos were taken with a Canon EOS D6 camera with a Canon MP-E $5 \times$ macrozoom and a Yongnuo YN 14 EX Macro Ring Flash. Multiple pictures were taken with the aid of a Stackshot macro-stacking

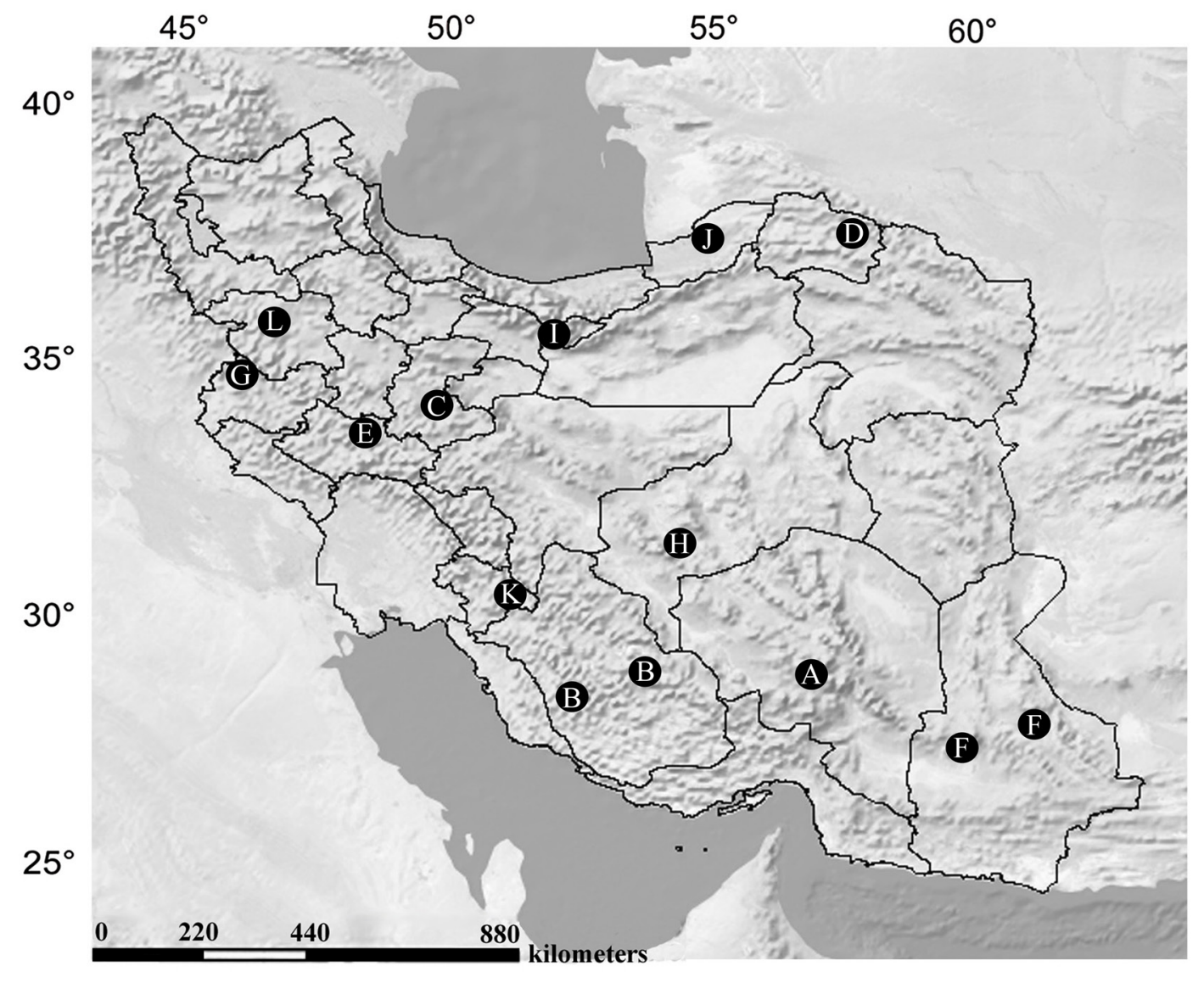

Fig. 2. Distribution of the Eumerus tricolor species group in Iran. A. Kerman prov., Baft (E. atricolorus Gilasian \& van Steenis sp. nov.). B. Fars prov., Meimand and Mian Jangal (E. brevipilosus Gilasian \& van Steenis sp. nov., E. longitarsis Peck, 1979). C. Markazi prov., Haftad Qolleh Protected Area, Chekab Valley (E. chekabicus Gilasian \& van Steenis sp. nov., E. coeruleus (Becker, 1913), E. jacobsoni Becker, 1913, E. longitarsis, E. ovoformus Gilasian \& van Steenis sp. nov., E. pilosipedes Gilasian \& van Steenis sp. nov., E. tadzhikorum Stackelberg, 1949, E. vallicolous Gilasian \& van Steenis sp. nov.). D. Khorasan prov., Ghoochan (E. coeruleus, E. hissaricus Stackelberg, 1949, E. tadzhikorum). E. Lorestan prov., Alishtar and Doroud (E. falsus Becker, 1922), E. kazanovzkyae Paramonov, 1927). F. Sistan \& Balouchestan prov., Bazman and Khash (E. coeruleus, E. jacobsoni, E. persarum Stackelberg, 1961, Eumerus sp.). G. Kermanshah prov., Paveh (E. kazanovzkyae). H. Yazd prov., Yazd (E. persarum). I. Tehran prov., Damavand and Lar (E. persicus Stackelberg, 1949, E. richteri Stackelberg, 1960). J. Golestan prov., Golestan National Park, Almeh (E. tadzhikorum). K. Kohkilouyeh \& Boyerahmad prov., Yasuj (E. tricolor (Fabricius, 1798)). L. Kordestan prov. (E. tadzhikorum). 
rail and stacked with Zerene Stacker. These stacked images were further edited with the software GIMP ver. 2.8.22 and combined into the colour plates.

Label data of specimens are given verbatim, within double quotation marks. Each line on a label is separated by a single forward slash (/) and labels are separated by a double forward slash (//). The morphological terminology used in this paper follows Thompson (1999) for external morphology and Doczkal (1996) for the male genitalia. The measurements were made using a micrometer as follows: overall length of specimens (in $\mathrm{mm}$ ) is measured in lateral view from the anterior margin of the head, excluding the antenna, to the end of the abdomen; length of basoflagellomere is measured from its joint to pedicel dorsally and width of basoflagellomere is measured at its maximum width (Fig. 11G). The following measurements are done as explained in van Steenis et al. (2017) and repeated here: width of head in frontal and dorsal views is measured at its maximum width; width of face is measured below the antennae; width of ocellar triangle is measured over the posterior ocelli dorsally; length of ocellar triangle is measured from the anterior end of the anterior ocellus to the midline posterior of the posterior ocelli; length of frontal triangle is measured from the anterior corner of the eye contiguity to the posterior corner of the lunule in dorsal view; length of vertical triangle is measured from the posterior corner of the eye contiguity to the anterior ocellus in dorsal view; the eye contiguity is the length in between the previous two measurements; width of vertex in dorsal view is measured between the posterior corner of the eyes (a) and over the posterior ocelli (b).

\section{Comparative material}

All new species are thoroughly compared with their closest relatives and available type specimens. A list of the additional examined type specimens is provided here. The examined type material for Iranian species is given in connection with the respective species (see below).

Eumerus aurofinis Grković, Vujić \& Radenković in Grković et al., 2015

Paratypes

GREECE • 1 O̊; "Greece / Samos, Pirgos. ulaz u klisuru / 08.06.2012 / Leg. Vujić A., Likov L. // Paratype E. aurofinis / Grković, Vujić \& / Radenković, 2015 [red label]”; JSA.

TURKEY • 1 क; "Bozdağ Mountain / near Çamurhamami Köyü / 7.6.2014, 38.452905 28.05707 / Leg. Vujić, Ačanski alt: 291 m // Paratype E. aurofinis / Grković, Vujić \& / Radenković, 2015 [red label]”; JSA.

Eumerus coeruleithorax Peck, 1969

Holotype

KAZAKHSTAN • Õ; "valley r. Mashat / South Kazakhstan / Peck 30.V.1964 // 473 // Holotypus / Eumerus coeruleithorax / Peck [red label]"; ZISP.

Eumerus mesasiaticus Stackelberg, 1949

\section{Holotype}

TAJIKSTAN • đ; "Dere-kul., L. / niz. Vakhsha 21.III.1944 / Stackelberg // 467 // Eumerus Typ '46 / mesasiaticus ô,, sp. n. / Stackelberg det. // Holotypus '49 / Eumerus / mesasiaticus Stack [red label]”; ZISP.

Eumerus pamirorum Stackelberg, 1949

\section{Holotype}

TAJIKISTAN • ○; “Khorog on the river. Gunt / Shugnan 15.IX.1943 / Stackelberg // Eumerus Typ. '46 / pamirorum sp.n. / Stackelberg det. // Holotypus '49 / Eumerus / pamirorum Stack. [red label, partly handwritten]"; ZISP. 
Eumerus sarybulunis Peck, 1972

Holotype

KYRGYZSTAN • đ; "Sary-Bulun / Kyrgyzstan height 1400 m / Peck 18.VI.1970 // Holotypus §ิ / Eumerus sarybu- / lunis Peck sp.n.[red label, partly handwritten]"; ZISP.

\section{Results}

\section{Taxonomy}

Class Insecta Linnaeus, 1758

Order Diptera Linnaeus, 1758

Family Syrphidae Latreille, 1802

Tribe Merodontini Edwards, 1915

Genus Eumerus Meigen, 1822

\section{The Iranian species of the Eumerus tricolor species group}

A total of 17 species belonging to the Eumerus tricolor group are recorded from Iran, six of which are new to science, i.e., Eumerus atricolorus Gilasian \& van Steenis sp. nov., E. brevipilosus Gilasian \& van Steenis sp. nov., E. chekabicus Gilasian \& van Steenis sp. nov., E. ovoformus Gilasian \& van Steenis sp. nov., E. pilosipedes Gilasian \& van Steenis sp. nov. and E. vallicolus Gilasian \& van Steenis sp. nov., and three species are newly reported from Iran, i.e., E. hissaricus Stackelberg, 1949, E. longitarsis Peck, 1979 and E. richteri Stackelberg, 1960.

\section{Diagnosis of the Eumerus tricolor species group}

The Eumerus tricolor species group can be identified by the combination of the following characters: basoflagellomere radially furrowed, apico-laterally with clearly demarcated, ellipsoidal fossa (Fig. 11AI); katepisternum ventrally, medially and dorsally pilose (as in character states 44A:0 and 44B0:1 and related figures in van Steenis \& Wyatt 2020); wing vein costa with a row of long posterodorsal setae basally (Fig. 8F); terga often more or less red coloured; anterior surstylus lobe undeveloped (Figs 18AF, 19A-E).

Eumerus atricolorus Gilasian \& van Steenis, sp. nov. urn:1sid:zoobank.org:act:8C5F4827-4544-4E7C-A326-3AFA864E06DC

Figs 3A, 6A, 9A, 11A, 12A, 13A-B, 18A, 20A, 22A

\section{Diagnosis}

Antenna brownish-black; eyes coalescent at one point; ocellar triangle almost equilateral; occiput narrow, less bulging; scutum without pollinose vittae, with short whitish pile; legs predominantly black; mesotrochanter slightly pollinose with pile ventrally; abdomen mostly reddish-brown. This species is closely related to E. mesasiaticus and E. richteri except for the following characters: basoflagellomere brownish-black (orange in E. mesasiaticus and E. richteri); scutum shiny black without pollinose vittae (with median longitudinal pollinose vittae in E. mesasiaticus); legs predominantly black except for brownish-orange apex of femora, basal orange narrow margin of tibiae and orange tarsomeres ventrally (basal $1 / 3-1 / 2$ of tibiae in E. mesasiaticus and basal $1 / 4-1 / 3$ of tibiae in E. richteri orange; tarsi in E. mesasiaticus and E. richteri mostly orange).

\section{Etymology}

The specific epithet 'atricolorus' [Latin] is derived from 'atricoloris' (black coloured), in reference to the deep black coloured thorax and legs. 


\section{Material examined}

Holotype

IRAN • O’; "IRAN: Kerman prov., Baft / Deh Sard, 2280 m. / 2845'0.2"N, 056³1'21.7"E, / 22.iv.2006, / leg. Gilasian // HOLOTYPUS O / Eumerus atricolorus / Gilasian \& van Steenis / 2020 [red label]”; HMIM.

\section{Description}

Male (Figs 3A, 6A)

MEASUREMENTS. Body length: $9.7 \mathrm{~mm}$; wing length: $7.2 \mathrm{~mm}$.

HeAD (Fig. 13A-B). Eyes short pilose, coalescent at one point; face nearly parallel-sided, mostly shiny black, weakly grey pollinose at lateral margin and covered with long whitish pile; frontal triangle predominantly shiny black, weakly grey pollinose laterally and with dense whitish pile; head in frontal view about 3.3 times as wide as face; frontal triangle about 1.4 times as long as vertical triangle; vertical triangle mostly shiny black, weakly pollinose laterally and with whitish pile; ocellar triangle almost equilateral; ocellar triangle weakly pollinose, with whitish pile, and nearly as long as vertical triangle; distance between posterior ocelli to posterior margin of eye about 0.65 times as long as ocellar triangle; occiput grey pollinose, with light pile; frontal triangle 1.4 times as wide as ocellar triangle; vertex at posterior corner of eyes 1.35 times as wide as vertex over posterior ocelli; head in dorsal view 4.7 times as wide as vertex at posterior corner of eyes; antenna including arista entirely brownishblack; basoflagellomere rounded apicoventrally, 1.3 times as long as wide; arista 1.5 times as long as basoflagellomere (Fig. 11 A).

Thorax. Scutum and scutellum shiny black with short whitish pile; scutum without pollinose vittae; scutellum with marginal rim; pleurae shiny black, covered with short whitish pile except for bare meron and katepimeron; metasternum pilose.

Legs (Fig. 9A). Legs predominantly shiny black except for brownish-orange apex of femora, basal narrow orange margin of tibiae and orange tarsomeres ventrally; short whitish pilose; mesotrochanter weakly pollinose and with pile ventrally; metatarsus with a short tuft of orange pile ventrally; metafemur simple, slightly enlarged, about 3.75 times as long as wide, ventral pile very short and about $1 / 6_{-1}-1 / 7$ of width of metafemur; anteroventral and posteroventral margins of metafemur each with a row of 10 respectively 7 black setae apically.

WING. Hyaline; entirely microtrichose; calypters yellowish-white; halter brownish-orange.

AвDOMEN. Predominantly reddish-brown; tergum I black with whitish pile laterally; terga II-IV reddishbrown, white pilose, each with a pair of oblique maculae of white pollinosity; tergum II with a median black 'pewter chalice'-shaped vitta; tergum III with a median longitudinal black vitta on anterior half; sterna reddish-brown, yellowish pilose; sternum IV almost square, with median V-shaped incision posteriorly (Fig. 12A).

Genitalia (Figs 18A, 20A, 22A). Hypandrium simple; aedeagal apodeme narrow in lateral view; cercus semi-rectangular, convex dorsally; posterior lobe of surstylus (lateral view) uniformly rounded apically, with 4-5 rows of short median setulae; posterior lobe of surstylus (dorsal view) sinuous-shaped on outer side; inner accessory lobe of surstylus with short pile.

\section{Female}

Unknown. 


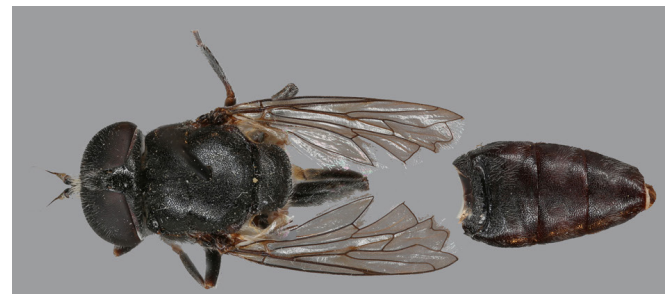

A

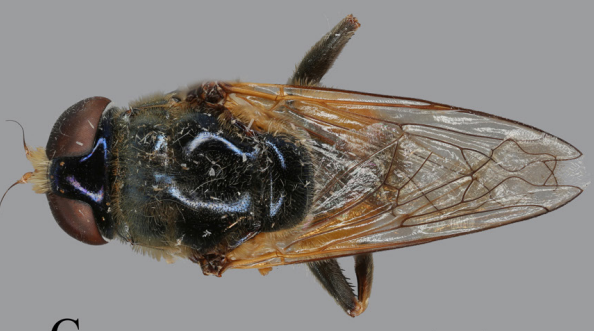

$\mathrm{C}$
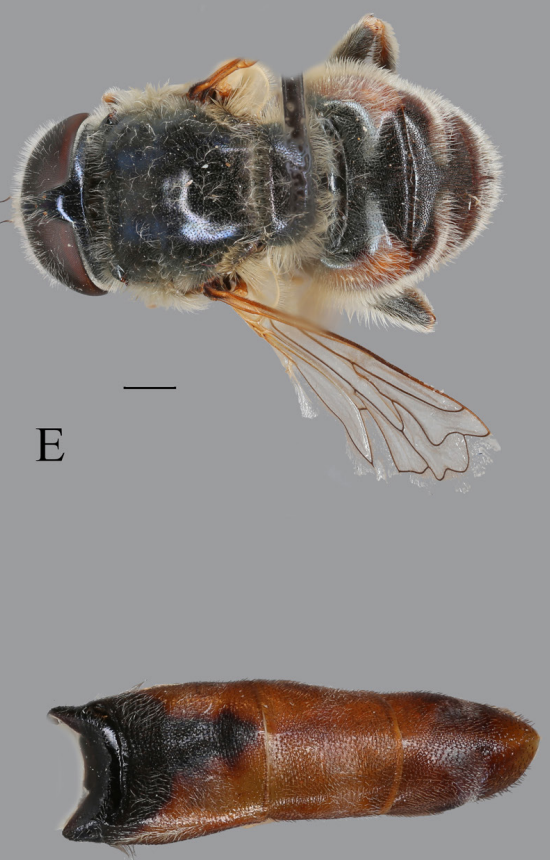

G

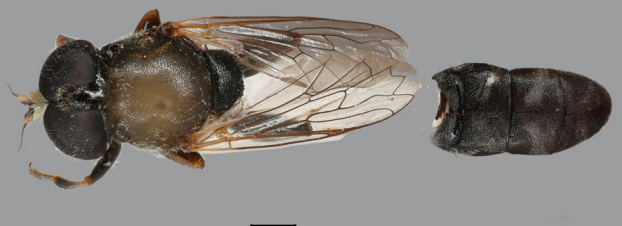

B

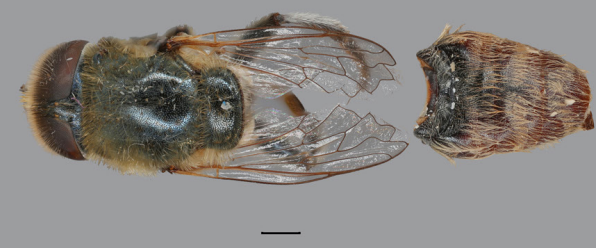

$\mathrm{D}$
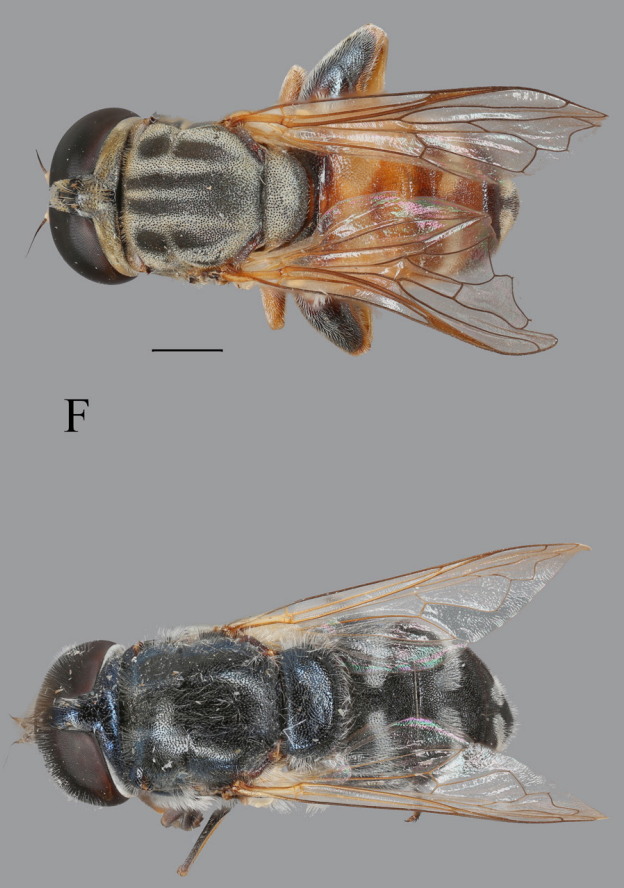

$\mathrm{H}$

Fig. 3. Adult habitus, $\partial$, dorsal view. A. Eumerus atricolorus Gilasian \& van Steenis sp. nov., holotype (HMIM). B. E. brevipilosus Gilasian \& van Steenis sp. nov., holotype (HMIM). C. E. falsus Becker, 1922, Chekab Valley, Iran (HMIM). D. E. chekabicus Gilasian \& van Steenis sp. nov., holotype (HMIM). E. E. coeruleus (Becker, 1913), Chekab Valley, Iran (JSA). F. E. jacobsoni Becker, 1913, Chekab Valley, Iran (JSA). G. E. kazanovzkyae Paramonov, 1927, abdomen, Paveh, Iran (HMIM). H. E. longitarsis Peck, 1979, Chekab Valley, Iran (JSA). Scale bars $=1.0 \mathrm{~mm}$. 


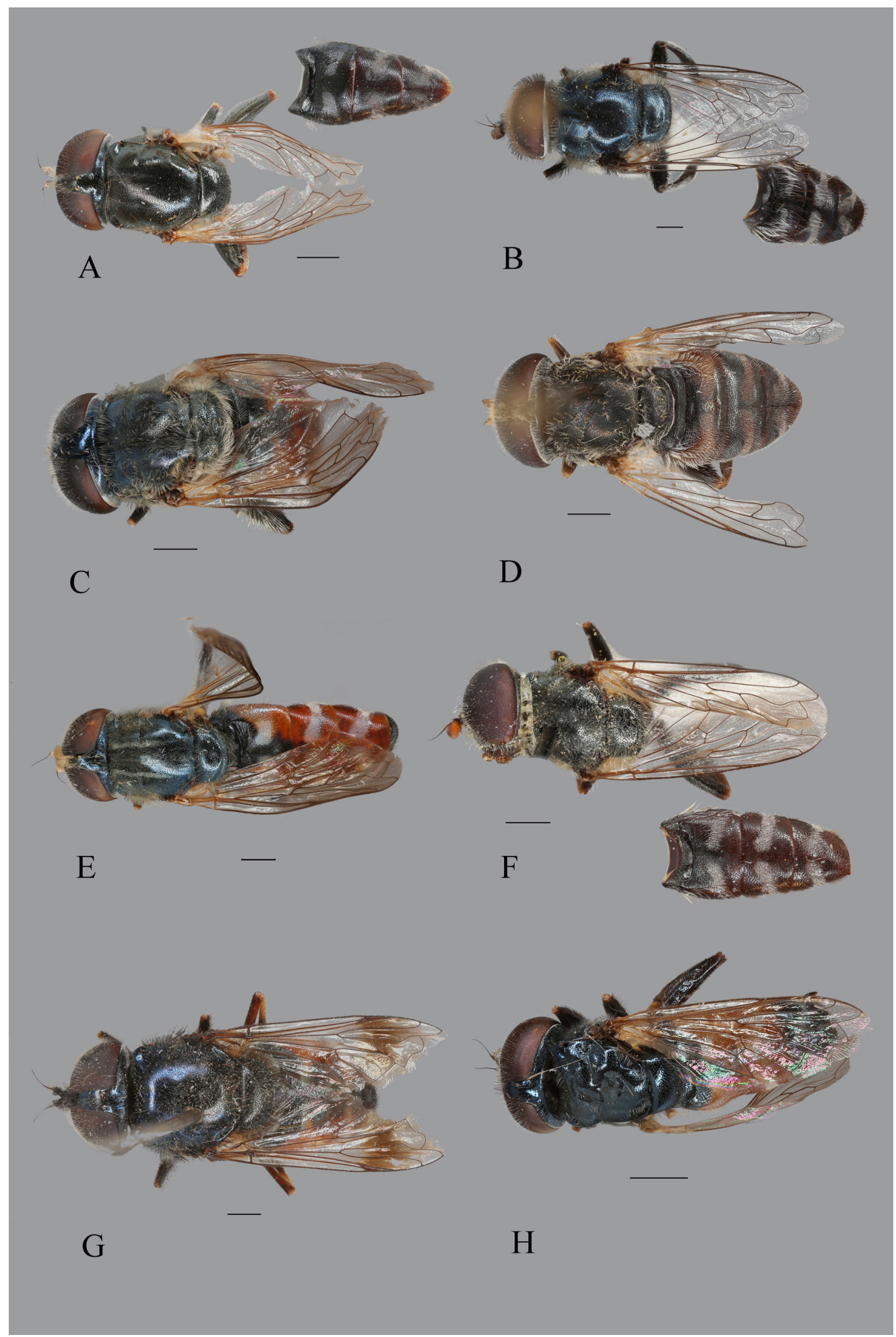

Fig. 4. Adult habitus, $\partial^{\lambda}$, dorsal view. A. Eumerus sp., Khash, Iran (HMIM). B. E. hissaricus Stackelberg, 1949, Ghoochan, Iran (HMIM). C. E. ovoformus Gilasian \& van Steenis sp. nov., holotype (HMIM). D. E. persarum Stackelberg, 1961, Yazd, Iran (JSA). E. E. pilosipedes Gilasian \& van Steenis sp. nov., holotype (HMIM). F. E. richteri Stackelberg, 1960, Lar, Iran (HMIM). G. E. tadzhikorum Stackelberg, 1949, Chekab Valley, Iran (JSA). H. E. vallicolus Gilasian \& van Steenis sp. nov., holotype (HMIM). Scale bars $=1.0 \mathrm{~mm}$. 


\section{Distribution}

Iran.

Eumerus brevipilosus Gilasian \& van Steenis sp. nov.

urn:lsid:zoobank.org:act:D239E0A4-F597-444E-8034-B5B1C67A55A0

Figs 3B, 5A, 6B, 8A, 9B-C, 11B-C, 12B, 13C-D, 14A-B, 18B, 20B, 22B

\section{Diagnosis}

This species is closely related to $E$. aurofinis except for the following characters: body length about $8 \mathrm{~mm}$, not densely punctuated (with coarse and dense punctuation in E. aurofinis); wing hyaline (infuscated in $E$. aurofinis in the area posterior to intersection of veins $\mathrm{R}_{2+3}$ and $\mathrm{R}_{4+5}$ ); metafemur slightly enlarged (strongly enlarged in E. aurofinis); aedeagal apodeme long, narrow and abruptly bent apically (short, wide and without bend in E. aurofinis) (see Grković et al. 2015: 367, fig. 4C); posterior lobe of surstylus in lateral view wider than in E. aurofinis (see Grković et al. 2015: 367, fig. 4A).

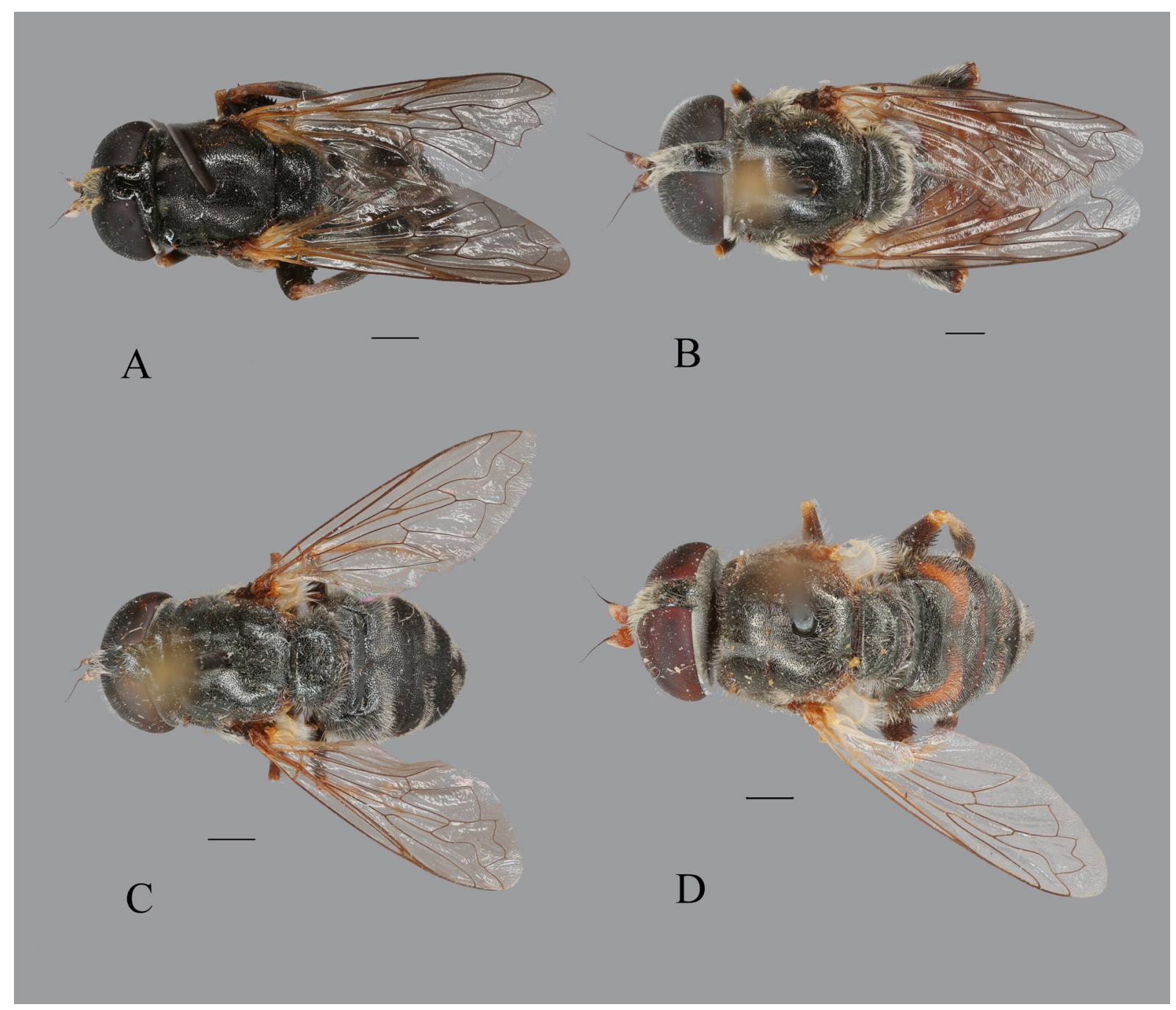

Fig. 5. Adult habitus, $q$, dorsal view. A. Eumerus brevipilosus Gilasian \& van Steenis sp. nov., paratype (HMIM). B. E. coeruleus (Becker, 1913), Ghoochan, Iran (HMIM). C. E. longitarsis Peck, 1979, Mian Jangal, Iran (JSA). D. E. persarum Stackelberg, 1961, Bazman, Iran (JSA). Scale bars $=1.0 \mathrm{~mm}$. 


\section{Etymology}

The specific epithet 'brevipilosus' [Latin] is derived from 'brevis' (short) and 'pilosus' (pilose), in reference to the very sparse and short pile on the head, thorax and abdomen rarely seen in the genus Eumerus.

\section{Material examined}

\section{Holotype}

IRAN - ${ }^{\top}$; "IRAN: Fars prov., Meimand / Firouzabad, Kuhe - Sefidan / $28^{\circ} 56^{\prime} 0.34^{\prime \prime} \mathrm{N}, 052^{\circ} 48^{\prime} 58.0^{\prime \prime} \mathrm{E}$ / 2080m., 9.iv.2006 / E. Gilasian // HOLOTYPUS § / Eumerus brevipilosus / Gilasian \& van Steenis / 2020 [red label]"; HMIM.

\section{Paratypes}

IRAN • 4 O $\$$; same collection data as for holotype; HMIM.

\section{Description}

Male (Figs 3B, 6B)

MEASUREMENTs. Body length: $7.8 \mathrm{~mm}$; wing length: $5.5 \mathrm{~mm}$.

HEAD (Fig. 13C-D). Eyes short and white pilose, dichoptic, 2-3 ommatidia spaced; face nearly parallelsided, weakly grey pollinose, with whitish pile; frontal triangle weakly grey pollinose, entirely covered with dense and long white pile; head in frontal view 3.2 times as wide as face; frontal triangle almost 1.3 times as long as vertical triangle; vertical triangle almost entirely shiny black, with yellowish pile; ocellar triangle nearly equilateral; ocellar triangle bulging and shiny black, with black pile, about as long as vertical triangle; distance between posterior ocelli to posterior margin of eye nearly 0.8 times as long as ocellar triangle; occiput light grey pollinose, with light pile; frontal triangle nearly 1.6 times as wide as ocellar triangle; vertex at posterior corner of eyes 1.15 times as wide as vertex over posterior ocelli; head in dorsal view 4.5 times as wide as vertex at posterior corner of eyes; scape brown; pedicel yellowish brown; basoflagellomere orange, 1.2 times as long as wide; arista brown, 1.3 times as long as basoflagellomere (Fig. 11B).

THORAX. Scutum and scutellum shiny black with very short yellowish pile; scutum with two narrow median pollinose vittae reaching to median suture; anterior part of median vittae semi-triangular; posterolateral part of scutum with a longitudinal row of black setulae above base of wing; scutellum with marginal rim; pleurae shiny black; anepisternum, katepisternum and anepimeron covered with short yellowish pile.

LEGS (Fig. 9B). Legs shiny black, with yellowish short pile; procoxa orange apically; femora predominantly black except for orange apical tip and basal narrow orange margin, basal half and apex of tibiae orange; tarsi mostly orange except for brownish-black dorsally; metafemur simple, slightly enlarged, about 3 times as long as wide, with very short yellowish pile ventrally; anteroventral and posteroventral margins of metafemur each with a row of 8 respectively 5 black setae in about apical half.

WING. Entirely microtrichose; vein $\mathrm{R}_{4+5}$ nearly straight; calypters whitish; halter yellowish-orange.

AвDOMEN. Black, covered with very short yellowish pile except for long whitish pile on tergum II anterolaterally; terga II-IV each with a pair of lunulate-shaped oblique maculae of white pollinosity; sterna brown, with yellowish short pile; sternum IV rectangular, with rounded posterolateral corners and with median wide V-shaped incision posteriorly (Fig. 12B). 
Genitalia (Figs 18B, 20B, 22B). Hypandrium simple; aedeagal apodeme in lateral view narrow and abruptly bent apically; cercus semi-rectangular; posterior lobe of surstylus in lateral view thumb-shaped apically and in dorsal view uniformly rounded apically and entirely covered with short setulae dorsally; inner accessory lobe of surstylus with short pile.

Female (Figs 5A, 8A, 9C, 11C, 14A-B)

Body length: $7.8-8.2 \mathrm{~mm}$; wing length: $6.0-6.5 \mathrm{~mm}$. Same as male except for sexual dimorphism and for the following characters: frons shiny black, weakly pollinose laterally and with short yellowish pile; vertex at posterior corner of eyes as wide as vertex over posterior ocelli; head in dorsal view 4 times as wide as vertex at posterior corner of eyes; scutum with median narrow pollinose vittae reaching to $1 / 3$ behind median suture; anepisternum, katepisternum and anepimeron covered with very short yellowish pile.

\title{
Distribution
}

Iran.

\author{
Eumerus chekabicus Gilasian \& van Steenis sp. nov. \\ urn:1sid:zoobank.org:act:3BCD6EB2-919A-4ECD-81BE-CCC18A3D5493 \\ Figs 3D, 6D, 9D, 11D, 12C, 13G-H, 18C, 20C, 22C
}

\section{Diagnosis}

This species differs from E. grandis Meigen, 1822, E. ovatus Loew, 1848 and E. sinuatus Loew, 1855 by the following characters: eyes with long brownish pile (with long light brown pile in E. sinuatus and E. ovatus and short white pile in E. grandis); vertical triangle flat like in E. sinuatus and E. ovatus (bulging vertical triangle in E. grandis); eyes holoptic, eye contiguity long like in E. grandis and E. ovatus (dichoptic eyes in E. sinuatus); ocellar triangle isosceles in E. chekabicus sp. nov., E. grandis and $E$. ovatus, posteriorly rather broad in E. chekabicus sp. nov. (rather narrow in E. grandis and broad in E. ovatus), ocellar triangle in E. sinuatus equilateral; vertical triangle with mix of black pile posteriorly and yellow pile anteriorly like in E. grandis (entirely black pilose in E. ovatus and E. sinuatus); scutum shiny metallic, without median vittae like in E. ovatus (shiny bluish in E. sinuatus and shiny black with long median vittae in E. grandis); scutum with long brownish pile (with short brownish and black pile in E. grandis, long white pile in E. ovatus and long brownish and black pile in E. sinuatus); tergum IV entirely reddish-orange (mostly black in E. grandis except for narrow red portions anterolaterally; it is black with median dense white pile in E. ovatus and it is black medially, red anterolaterally and posteriorly in E. sinuatus); metafemur slightly enlarged, with long whitish pile anteriorly (enlarged with long pile posteriorly in $E$. grandis, slightly enlarged with rather long pile anteriorly in $E$. ovatus and narrow with long pile anteriorly in E. sinuatus); metatibia long whitish pilose (with short whitish pilosity in E. sinuatus and short brown to black pilosity in E. grandis and E. ovatus).

\section{Etymology}

The name 'chekabicus' [Latin, adjective] refers to the Chekab Valley in the Haftad Qolleh Protected Area, Markazi province, where the holotype was collected.

\section{Material examined}

\section{Holotype}

IRAN • Õ; "IRAN: Markazi prov., Haftad- / Qolleh Protected Area, / Chekab Valley, 2219 m, / $34^{\circ} 07^{\prime} 0.5^{\prime \prime} \mathrm{N}, 050^{\circ} 16^{\prime} 25.3^{\prime \prime} \mathrm{E}, / 25 . \mathrm{v}-15 . v i .2016$, Malaise trap / near pool, E. Gilasian \& M. / ParchamiAraghi // HOLOTYPUS $\widehat{\sigma}$ / Eumerus chekabicus / Gilasian \& van Steenis / 2020 [red label]"; HMIM. 


\section{Description}

Male (Figs 3D, 6D)

MEASUREMENTS. Body length: $10.5 \mathrm{~mm}$; wing length: $7 \mathrm{~mm}$.

HeAd (Fig. 13G-H). Eyes long brownish pilose, holoptic, eyes contiguity almost 0.6 times as long as frontal triangle; face nearly parallel-sided, shiny black and covered with dense and long yellowish pile; frontal triangle shiny black, entirely covered with dense yellowish pile; head in frontal view 3.75 times as wide as face; frontal triangle 1.3 times as long as vertical triangle; vertical triangle shiny black, with yellowish pile; ocellar triangle isosceles; ocellar triangle shiny black, with mix of yellowish and black pile, 1.25 times as long as wide and nearly as long as vertical triangle; distance between posterior ocelli to posterior margin of eye about 0.7 times as long as ocellar triangle; occiput light grey pollinose, with yellowish pile; frontal triangle 1.25 times as wide as ocellar triangle; vertex at posterior corner of eyes 1.3 times as wide as vertex over posterior ocelli; head in dorsal view 5.5 times as wide as vertex at posterior corner of eyes; antennae brownish-black; basoflagellomere almost as long as wide; arista about 2.2 times as long as basoflagellomere (Fig. 11D).

THorax. Scutum and scutellum shiny metallic, weakly pollinose, with long and dense yellowish pile, without median pollinose vittae; posterolateral part of scutum with two black setulae above base of wing; scutellum with marginal rim; pleurae black; anepisternum, anepiemron and katepisternum with long yellowish pile.

LEGS (Fig. 9D). Legs black; metatrochanter orange at apex; metacoxa with long yellowish-white pile; pro- and mesofemora with long whitish pile posteriorly; mesofemur with short blackish pile anteriorly; metafemur simple, slightly enlarged, about 4 times as long as wide, with long whitish pile anteriorly; anteroventral and posteroventral margins of metafemur each with a row of 9 respectively 6 black setae in about apical half; pro- and mesotibiae with very short dense whitish pile dorsally and with long whitish pile posteriorly; metatibia with dense long whitish pile dorsally; metatarsus with short black pile dorsally and with tuft of dense orange pile ventrally; metasternum with long whitish pile.

WING. Sparsely microtrichose in basal half; vein $\mathrm{R}_{4+5}$ slightly sinuate; calypters yellowish-white; halter brownish-orange.

ABDomEn. Tergum I black with whitish pile; terga II-IV long whitish pilose, each with a pair of lunulashaped oblique maculae of white pollinosity; tergum II reddish-orange with a median black 'pewter chalice'-shaped vitta; tergum III mostly reddish-orange except median narrow black vitta; tergum IV entirely reddish-orange; sterna orange, long yellowish pilose; sternum IV rectangular, with rounded posterolateral corners and with median wide V-shaped incision posteriorly (Fig. 12C).

Genitalia (Figs 18C, 20C, 22C). Hypandrium simple; aedeagal apodeme wide in lateral view; posterior lobe of surstylus in lateral view narrowed toward apex, with a row of short and black setulae posteriorly and in dorsal view uniformly rounded apically with a strong median bend; inner accessory lobe of surstylus with short pile.

\section{Female}

Unknown.

Distribution

Iran. 


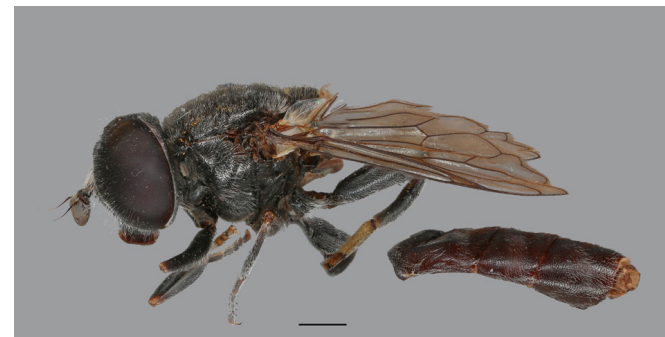

A
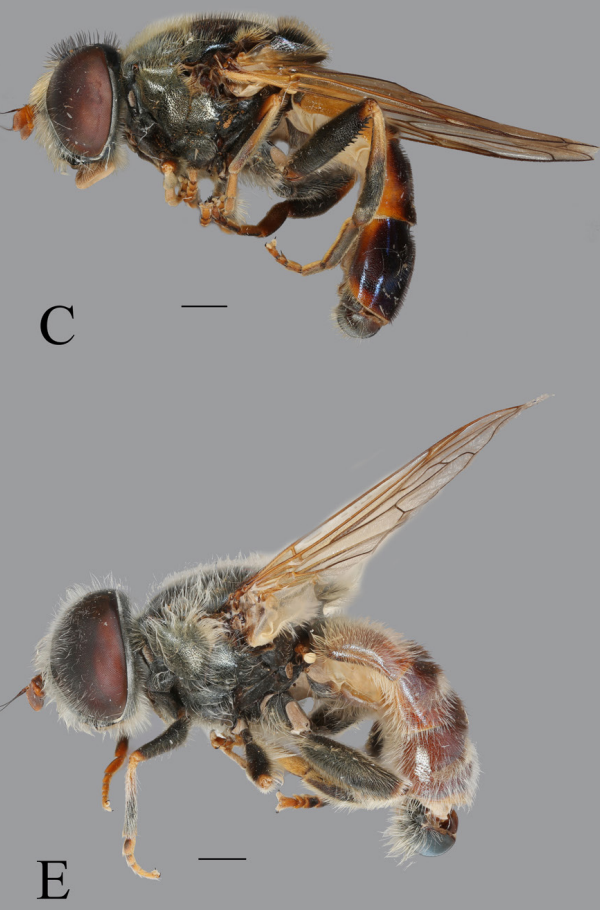

$\mathrm{E}$

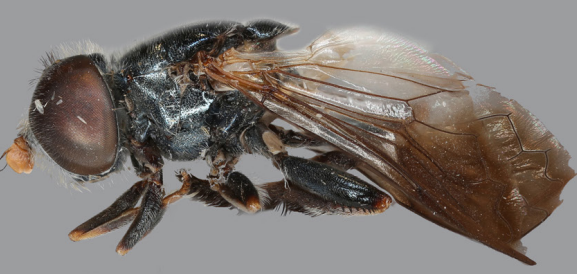

$\mathrm{G}$

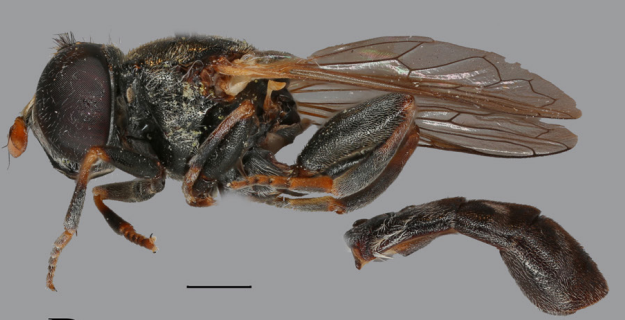

$\mathrm{B}$
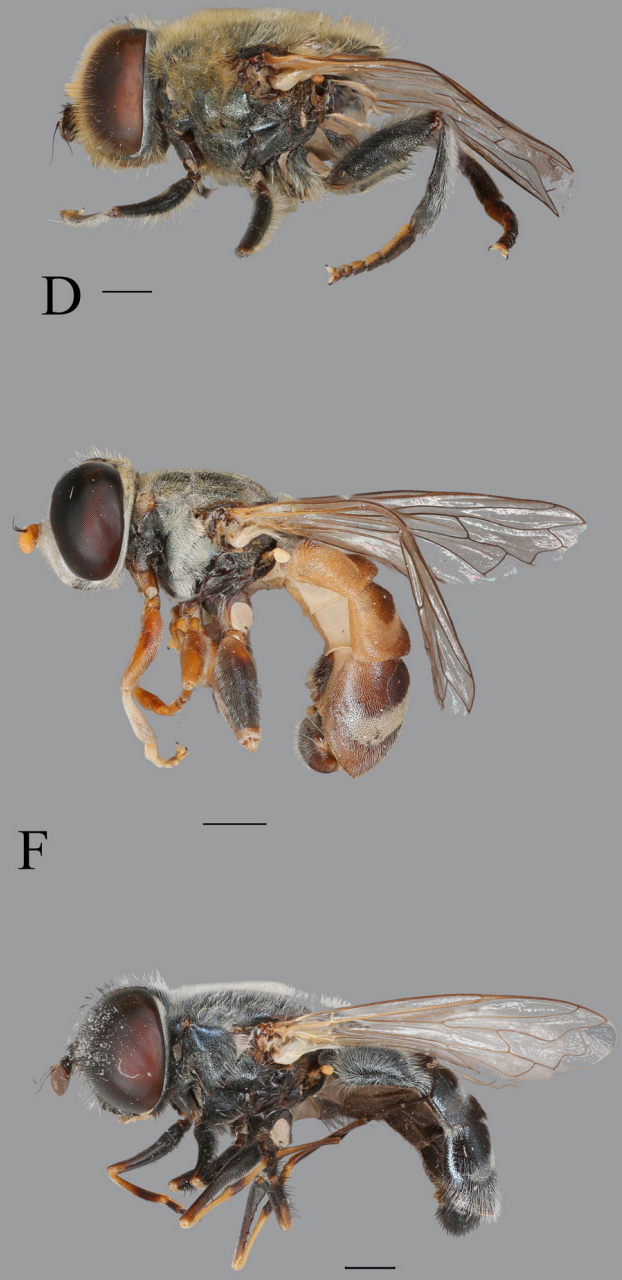

$\mathrm{H}$

Fig. 6. Adult habitus, $\widehat{O}$, lateral view. A. Eumerus atricolorus Gilasian \& van Steenis sp. nov., holotype (HMIM). B. E. brevipilosus Gilasian \& van Steenis sp. nov., holotype (HMIM). C. E. falsus Becker, 1922, Chekab Valley, Iran (HMIM). D. E. chekabicus Gilasian \& van Steenis sp. nov., holotype (HMIM). E. E. coeruleus (Becker, 1913), Chekab Valley, Iran (JSA). F. E. jacobsoni Becker, 1913, Chekab Valley, Iran (JSA). G. E. kazanovzkyae Paramonov, 1927, Paveh, Iran (HMIM). H. E. longitarsis Peck, 1979, Chekab Valley, Iran (JSA). Scale bars $=1.0 \mathrm{~mm}$. 


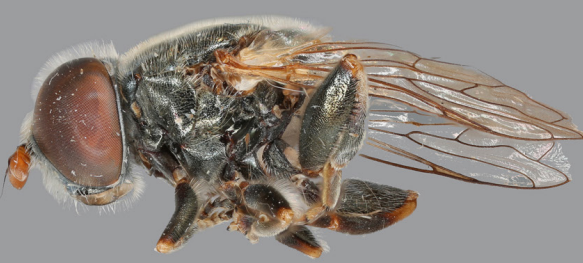

A

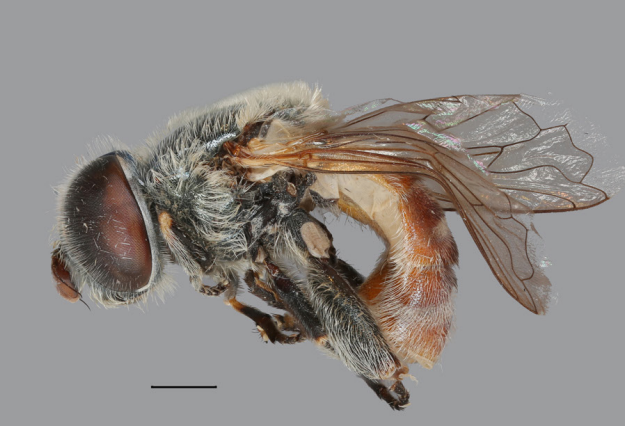

$\mathrm{C}$

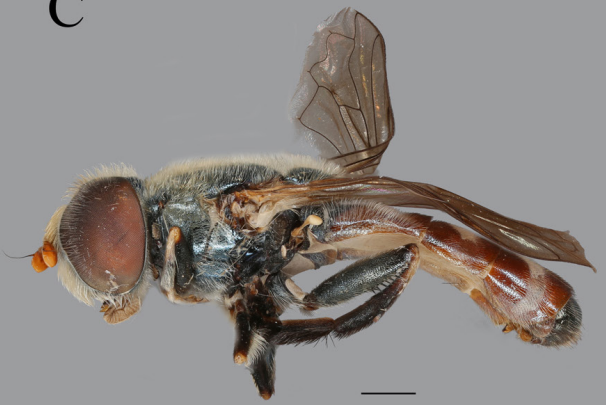

$\mathrm{E}$

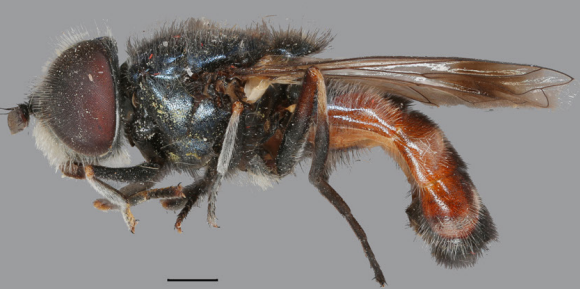

G

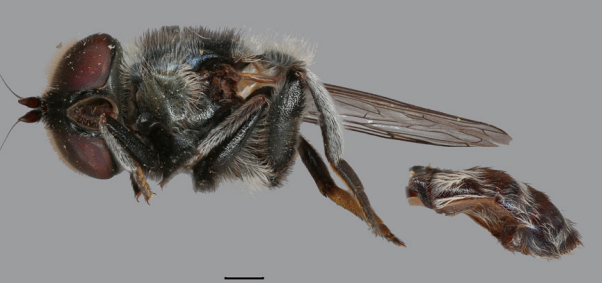

B

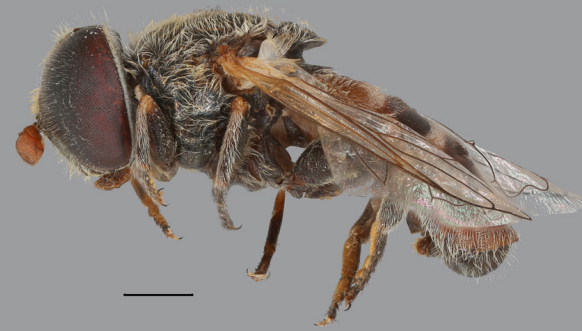

$\mathrm{D}$

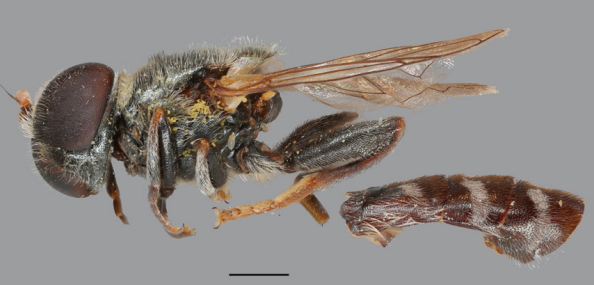

$\mathrm{F}$

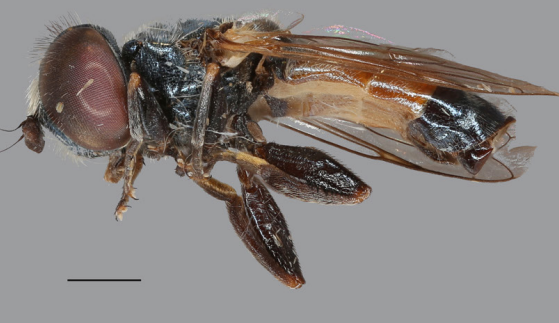

$\mathrm{H}$

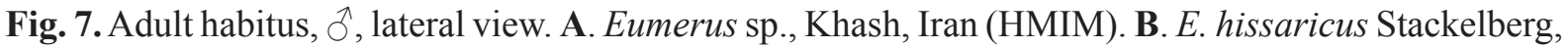
1949, Ghoochan, Iran (HMIM). C. E. ovoformus Gilasian \& van Steenis sp. nov., holotype (HMIM). D. E. persarum Stackelberg, 1961, Yazd, Iran (JSA). E. E. pilosipedes Gilasian \& van Steenis sp. nov., holotype (HMIM). F. E. richteri Stackelberg, 1960, Lar, Iran (HMIM). G. E. tadzhikorum Stackelberg, 1949, Chekab Valley, Iran (JSA). H. E. vallicolous Gilasian \& van Steenis sp. nov., holotype (HMIM). Scale bars $=1.0 \mathrm{~mm}$. 


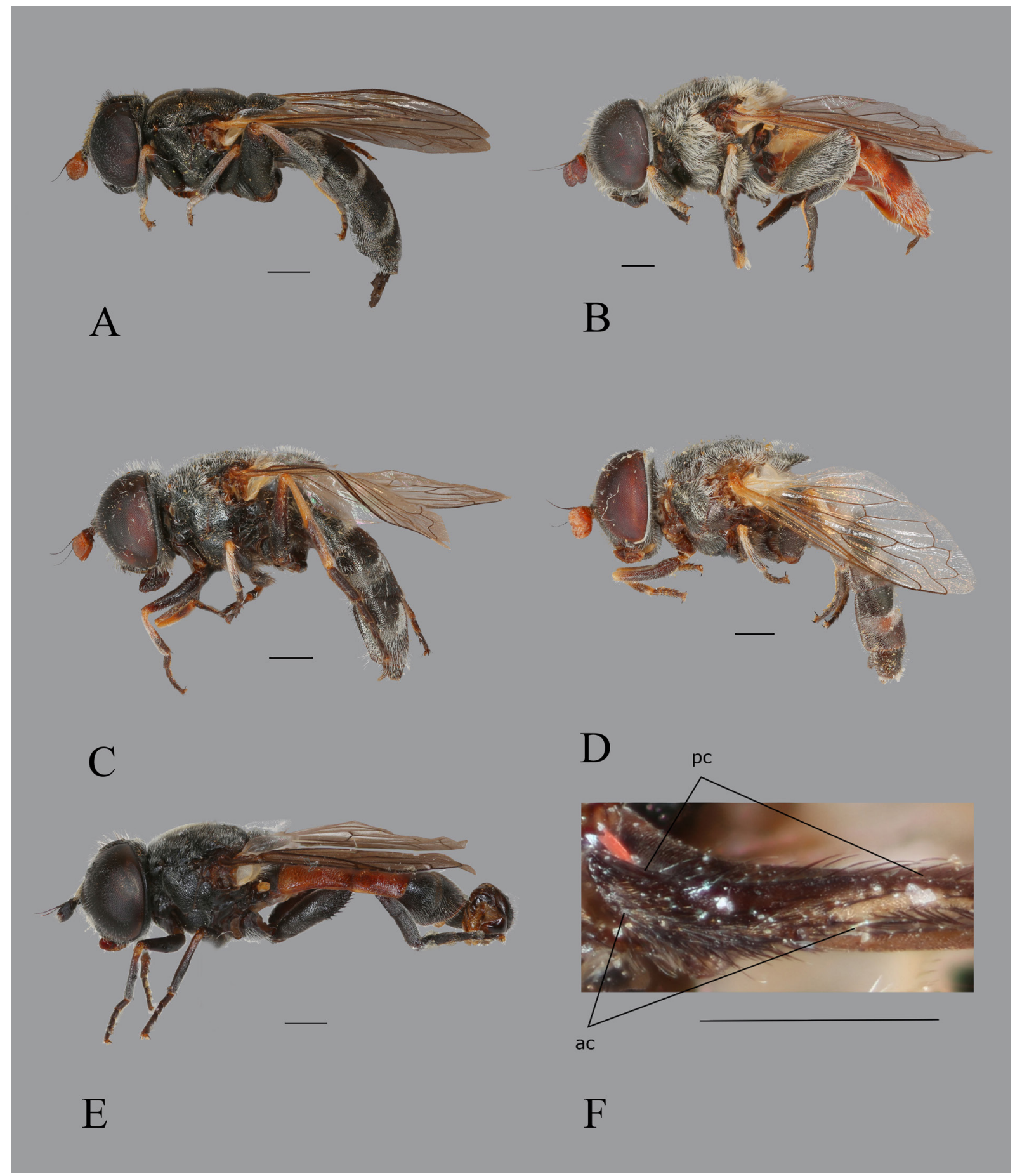

Fig. 8. A-E. Adult habitus, lateral view. F. Basicosta. A-D. Female. E-F. Male. A. Eumerus brevipilosus Gilasian \& van Steenis sp. nov., paratype (HMIM). B. E. coeruleus (Becker, 1913), Ghoochan, Iran (HMIM). C. E. longitarsis Peck, 1979, Mian Jangal, Iran (JSA). D. E. persarum Stackelberg, 1961, Bazman, Iran (JSA). E. E. tricolor (Fabricius, 1798), Paleochori, Greece (JSA). F. E. tadzhikorum Stackelberg, 1949, Chekab Valley, Iran (JSA). Scale bars $=1.0 \mathrm{~mm}$. Abbreviations: ac $=$ anterodorsal costal setae; $\mathrm{pc}=$ posterodorsal costal setae. 
Eumerus coeruleus (Becker, 1913)

Figs 3E, 5B, 6E, 8B, 14C-D, 15A-B, 18D, 20D, 22D

Lampetia coerulea Becker, 1913: 602.

\section{Diagnosis}

Eyes pilose (Fig. 14C-D), males dichoptic, distance between eyes in males less than width of ocellar triangle (Fig. 15A-B); face with whitish pile; ocellar triangle equilateral (Fig. 15A); basoflagellomere orange; scutum and scutellum with dense and long whitish pile (Figs 6E, 8B), weakly pollinose; pleura above metacoxa bare; legs long pilose; tarsi and basal half of tibiae orange; metafemur enlarged; metatarsus without dense thick black pile fringe; wing hyaline, entirely covered with microtrichia; vein $\mathrm{R}_{4+5}$ deeply sinuate (Fig. 5B); abdominal terga II-IV orange laterally; terga II-III with distinct median black vitta (Fig. 3E); male genitalia as in Figs 18D, 20D, 22D.

\section{Material examined}

Holotype

IRAN • Ō; "P. Beluchist. / 13.V.1901 // Lampetia coerulea Beck. / det. Becker // Holotypus Eumerus / coeruleus / Becker, 1913 [red label]"; ZISP.

\section{Other material}

IRAN • 1 क; "IRAN: Khorasan prov., Ghoochan / Emamgholi, Chovinli / 37²5'44.1"N, 058 31'57.3"E, / 1746 m.; 30.v.2006 / E. Gilasian // Eumerus coeruleus / (Becker, 1913)"; HMIM • 1 o; same collection

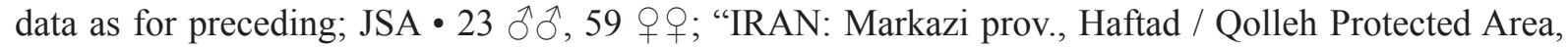
/ Chekab Valley, $2219 \mathrm{~m}, / 3^{\circ} 07^{\prime} 0.5^{\prime \prime} \mathrm{N}, 050^{\circ} 16^{\prime} 25.3^{\prime \prime} \mathrm{E}$, / 25.v-15.vi.2016, Malaise trap / near pool, E. Gilasian \& M. / Parchami-Araghi // Eumerus coeruleus / (Becker, 1913)"; HMIM • 2 ồ సै; same collection data as for preceding; JSA.

\section{Distribution}

Central Asia, Iran (Sistan \& Balouchestan prov., Kuh-e Taftan; Khorasan and Markazi provinces) (Peck 1988).

\section{Eumerus falsus Becker, 1922}

Figs 3C, 6C, 13E-F

Eumerus rubriventris Becker, 1921: 67 (junior primary homonym of Eumerus rubriventris Macquart, 1829)

Eumerus latifrons Sack, 1932: 403.

Eumerus zarudnyi Stackelberg, 1949: 431.

Eumerus rufiventris Van Der Goot, 1964: 218.

\section{Diagnosis}

Eyes pilose (Fig. 13E-F), widely spaced, distance between eyes more than width of ocellar triangle (Fig. 13E); scutum and scutellum shiny metallic, weakly pollinose (Fig. 3C); scutum pilose with two bare longitudinal areas posteromedially; scutellum strongly arched basally in lateral view, more than half as high as long; legs predominantly black, tarsi and basal half of tibiae orange (Fig. 6C); metafemur slightly enlarged; metatarsus without dense thick black pile fringe; wing hyaline, almost entirely covered with microtrichia; abdominal terga II-III orange laterally. 


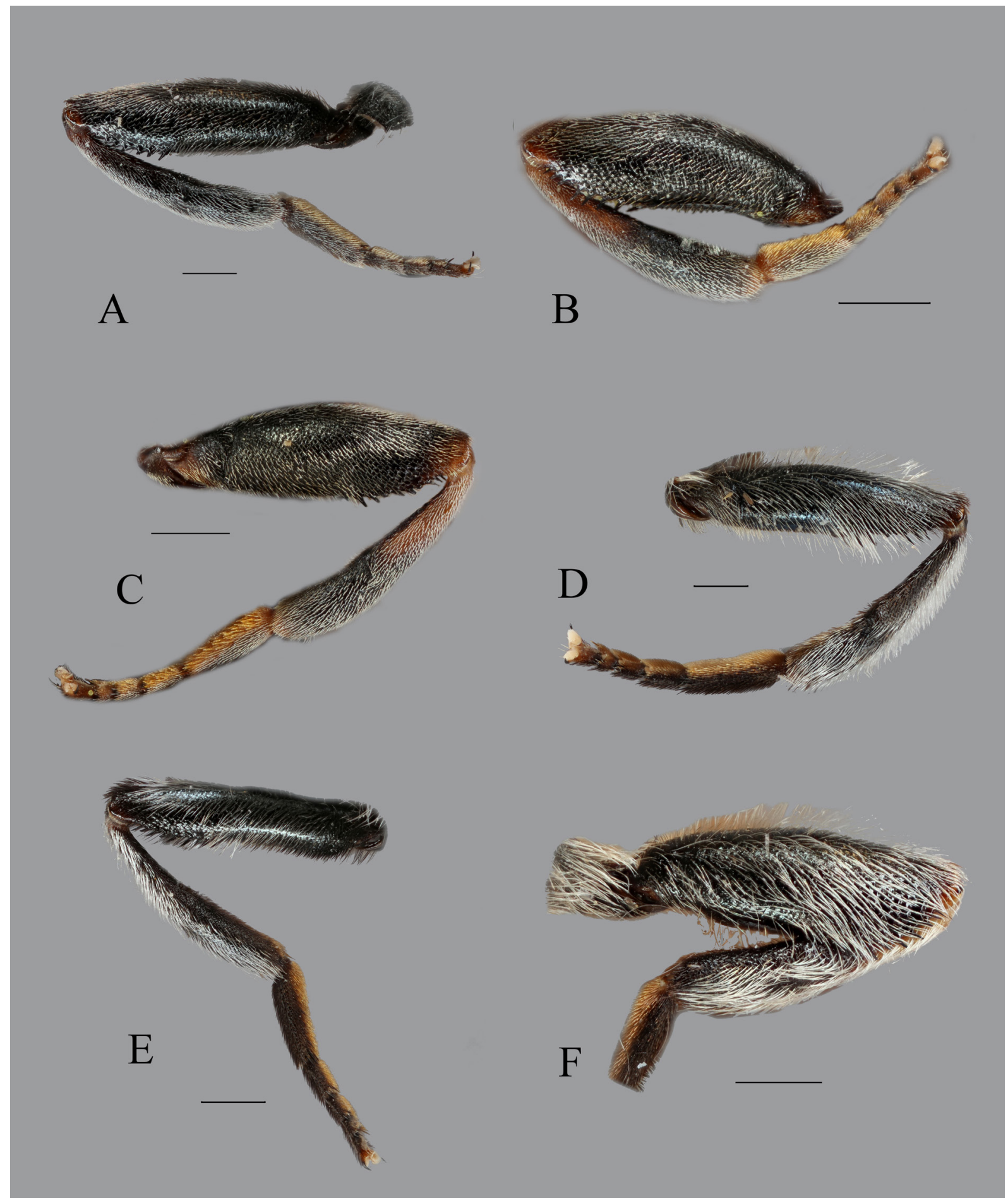

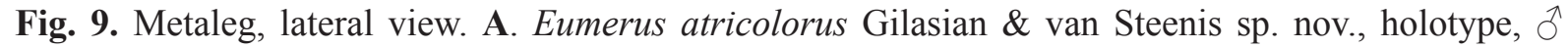
(HMIM). B. E. brevipilosus Gilasian \& van Steenis sp. nov., holotype, ô (HMIM). C. E. brevipilosus Gilasian \& van Steenis sp. nov., paratype,, (HMIM). D. E. chekabicus Gilasian \& van Steenis sp. nov., holotype, ô (HMIM). E. E. hissaricus Stackelberg, 1949, §, Ghoochan, Iran (HMIM). F. E. ovoformus

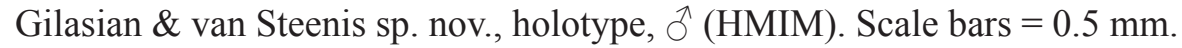




\section{Material examined}

\section{Holotype}

ISRAEL • +; "Carmel / 45576 IV // Typus [red label] // rubriventris / Becker // Eumerus falsus / Beck. / Stackelberg det. '[19]59 // Zool. Mus. / Berlin // Holotype + / Eumerus rubriventris / Becker, 1921 / det J. van Steenis, 2016 [red label]"; ZMHB.

\section{Other material}

IRAN - 1 O'; "IRAN: Markazi prov., Haftad / Gholleh Protected Area, / Chekab Valley, 2219m, / $34^{\circ} 07^{\prime} 05.3^{\prime \prime} \mathrm{N}, 050^{\circ} 16^{\prime} 25.3^{\prime \prime} \mathrm{E}, / 28 . \mathrm{V}-15 . V I .2016$, Malaise trap / near pool, E. Gilasian \& M. / PargamiAraghi"; HMIM.

\section{Distribution}

Central Asia, Iran (Lorestan prov., Alishtar; Markazi prov.), Israel, Transcaucasia, Turkey (Stackelberg 1949; Peck 1988).

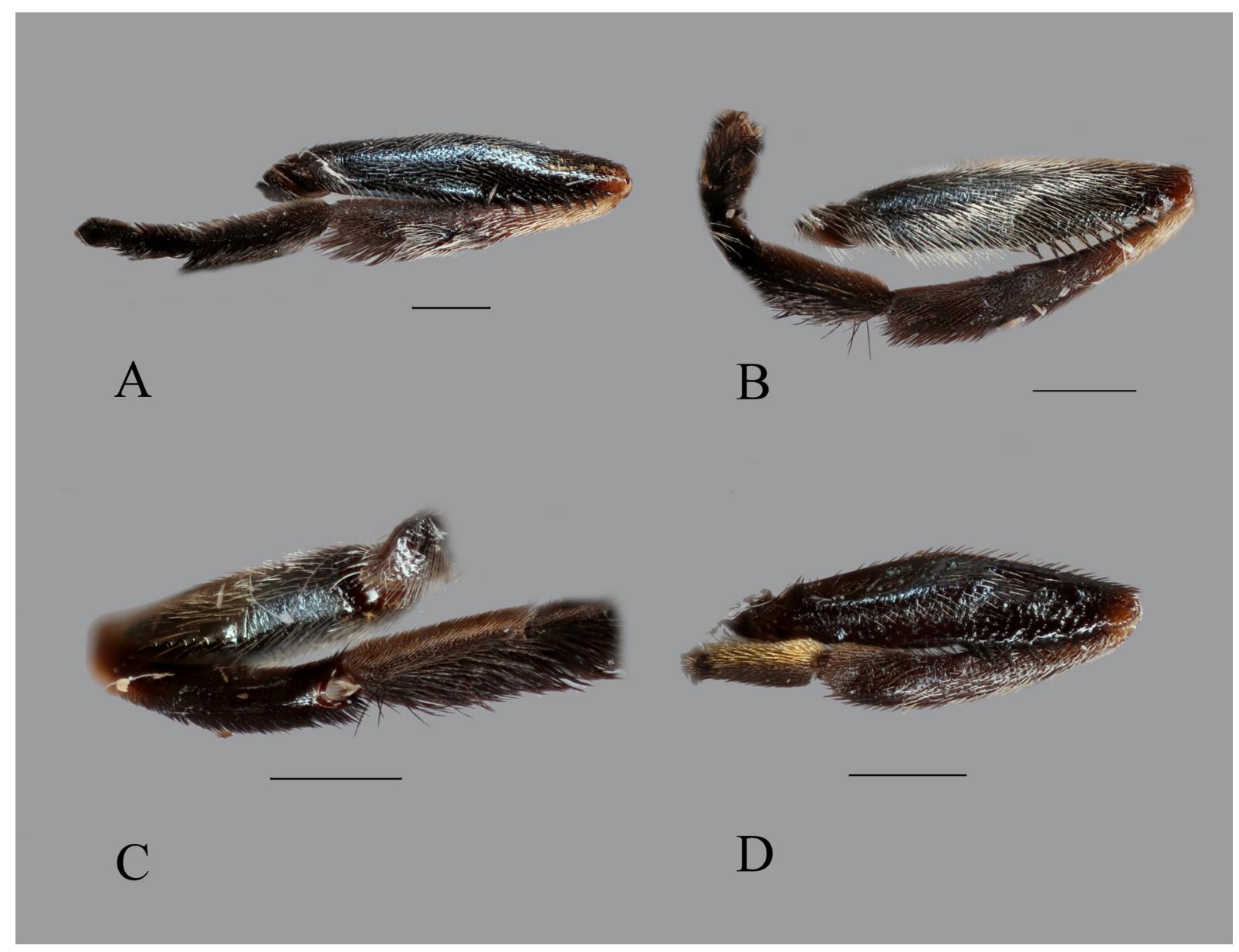

Fig. 10. Metaleg, đ̂, lateral view. A. Eumerus kazanovzkyae Paramonov, 1927, Paveh, Iran (HMIM). B. E. pilosipedes Gilasian \& van Steenis sp. nov., holotype (HMIM). C. E. pilosipedes Gilasian \& van Steenis sp. nov., details of tarsus, holotype (HMIM). D. E. vallicolus Gilasian \& van Steenis sp. nov., holotype (HMIM). Scale bars $=0.5 \mathrm{~mm}$. 
Eumerus hissaricus Stackelberg, 1949

Figs 4B, 7B, 9E, 11F, 12D, 16C-D, 19A, 21A, 23A

\section{Diagnosis}

Eyes pilose, males holoptic with long eye contiguity (Fig. 16C-D); face and frontal triangle black pilose; basoflagellomere brownish-black (Fig. 11F); scutum and scutellum shiny metallic, weakly pollinose (Fig. 4B); scutum with mix of white and black pile (Fig. 7B); legs black, tibiae with dense white pile dorsally (Fig. 9E); wing hyaline, basal cells bare of microtrichia; abdomen brownish-black (Fig. 4B); sternum IV rectangular, with rounded posterolateral corners and with median wide V-shaped incision posteriorly (Fig. 12D); male genitalia as in Figs 19A, 21A, 23A.

\section{Material examined}

\section{Lectotype}

TADJIKISTAN • đ̃; “"Gissar Tajikist. / 5.VII.35 / Gussakovsky // Eumerus Type. '46 / hissaricus, sp. n. / Stackelberg det. // 466 // Holotypus '49 / Eumerus / hissaricus Stack. [red label] // Lectotypus Eumerus / hissaricus Stack. design. V. Richter [red label]"; ZISP.

\section{Other material}

IRAN • 1 ○ं; "IRAN: Khorasan prov., Ghoochan / Emamgholi, Chovinli / 37²7'58.6"N, 058 34'45"E, / 2300 m.; 1.vi.2006 / E. Gilasian // Eumerus hissaricus / Stackelberg, 1949”; HMIM.

\section{Distribution}

Central Asia, Transcaucasia (Peck 1988). New record from Iran.

Eumerus jacobsoni Becker, 1913

Figs 3F, 6F, 15C-D

\section{Diagnosis}

Eyes bare, males holoptic with long eye contiguity (Fig. 15C-D); face white pilose; antennae yellowishorange; scutum and scutellum strongly pollinose, with very short yellowish pile and with 4 longitudinal blackish vittae (Fig. 3F); legs predominantly orange (Fig. 6F); metafemur strongly enlarged; abdomen predominantly yellowish-orange.

\section{Material examined}

Syntype

IRAN • Ō; "P. Beluchist / 10-13.V / 1901 // Eumerus / jacobsoni B. / Det Becker // Syntypus Eumerus / jacobsoni / Becker, 1913 [red label]”; ZISP.

\section{Other material}

IRAN • 40 ภㅅ, 62 우; “IRAN: Markazi prov., Haftad / Qolleh Protected Area, / Chekab Valley, $2219 \mathrm{~m}, / 3^{\circ} 07^{\prime} 0.5^{\prime \prime} \mathrm{N}, 050^{\circ} 16^{\prime} 25.3^{\prime \prime} \mathrm{E}$, / Malaise trap, 30 May-3 June / 2017, E. Gilasian \& M. /

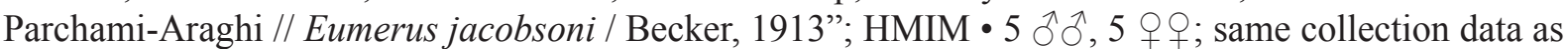
for preceding; JSA • 1 q; "Sistan \& Balouchestan/ Khash, S. W. Taftan, /3.vi.1996 / H. Mirzayans, H. Borumand \& A. Faghih // Eumerus jacobsoni / Becker, 1913”; HMIM.

\section{Distribution}

Afghanistan, Central Asia, Iran (Sistan \& Balouchestan prov., Kuh-e Taftan; Markazi prov.; Kerman prov.) (Peck 1988). 
Eumerus kazanovzkyae Paramonov, 1927

Figs 3G, 6G, 10A, 11E, 15E-F, 19B, 21B, 23B

\section{Diagnosis}

Eyes pilose, about 1 ommatidium spaced in males (Fig. 15E-F); face and frontal triangle white pilose; antennae yellowish-orange (Fig. 11E); scutum and scutellum shiny metallic, weakly pollinose, covered with short whitish pile; legs predominantly black, basal half of tibiae orange; metafemur with short ventral pile, about $1 / 8-1 / 7$ width of metafemur; metatibia with dense dorsal thick pile fringe apically (Fig. 10A); metatarsus pile fringe confined to antero-dorsal margin of metatarsus; wing strongly infuscated, reaching to posterior margin of wing (Fig. 6G); abdomen predominantly orange (Fig. 3G); male genitalia as in Figs 19B, 21B, 23B.

\section{Material examined}

Holotype

AZERBADJAN • đ̊; “N 314 // Arishia / Ordubad, 7.VI.[19]24 // Eumerus / kazanovzkyae / n.sp §̊ Typus / Paramonov det. [pink label, handwritten]"; ZISP.

\section{Other material}

IRAN • 1 O'; "IRAN, Kermanshah prov., / Paveh, Dodan, 3502'26.7"N / 04609'22.1"E, 16.vi. 2016/ 1500 m, Malaise trap, M. Zardoui// Eumerus kazanovzkyae / Paramonov, 1927”; HMIM.

\section{Distribution}

Iran (Lorestan prov., Doroud; Kermanshah prov.), Transcaucasia (Peck 1988; Bahirai et al. 2014).

Eumerus longitarsis Peck, 1979

Figs $3 \mathrm{H}, 5 \mathrm{C}, 6 \mathrm{H}, 8 \mathrm{C}, 14 \mathrm{E}-\mathrm{F}, 15 \mathrm{G}-\mathrm{H}$

\section{Diagnosis}

Eyes pilose (Figs 14E-F, 15H), about 1 ommatidium spaced in males (Fig. 15G); ocellar triangle isosceles; scutum and scutellum shiny metallic, weakly pollinose (Fig. $3 \mathrm{H}$ ), covered with white pile (Figs 6H, 8C); legs predominantly black; metaleg extremely long and slender; metatibia as long as metafemur; metatarsus distinctly longer than metatibia; abdomen black (Fig. 5C).

\section{Material examined}

Paratype

TADJIKISTAN • ơ; "Tadji., Gissar Mt. / us. Takob / Tien Shan h=1700 m / Peck 23.VII.1976 // Paratypus $\overparen{\curvearrowright} /$ Eumerus / longitarsis Peck [red label]"; ZISP.

\section{Other material}

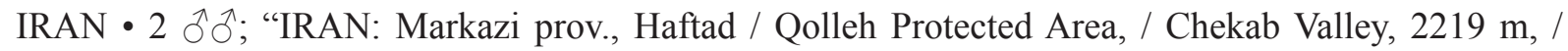
$34^{\circ} 07^{\prime} 0.5^{\prime \prime} \mathrm{N}, 050^{\circ} 16^{\prime} 25.3^{\prime \prime} \mathrm{E}$, / Malaise trap, 30 May-3 June / 2017, E. Gilasian \& M. / Parchami-Araghi // Eumerus longitarsis / Peck, 1979"; HMIM • 1 đo; same collection data as for preceding; JSA • 1 q; "S Iran / Mian Jangal / 30.5-5.6.1973 // Loc. no. 223 / Exp. Nat. Mus. / Praha”; JSA.

\section{Distribution}

Central Asia (Peck 1988; Grković 2019a). New record from Iran. 


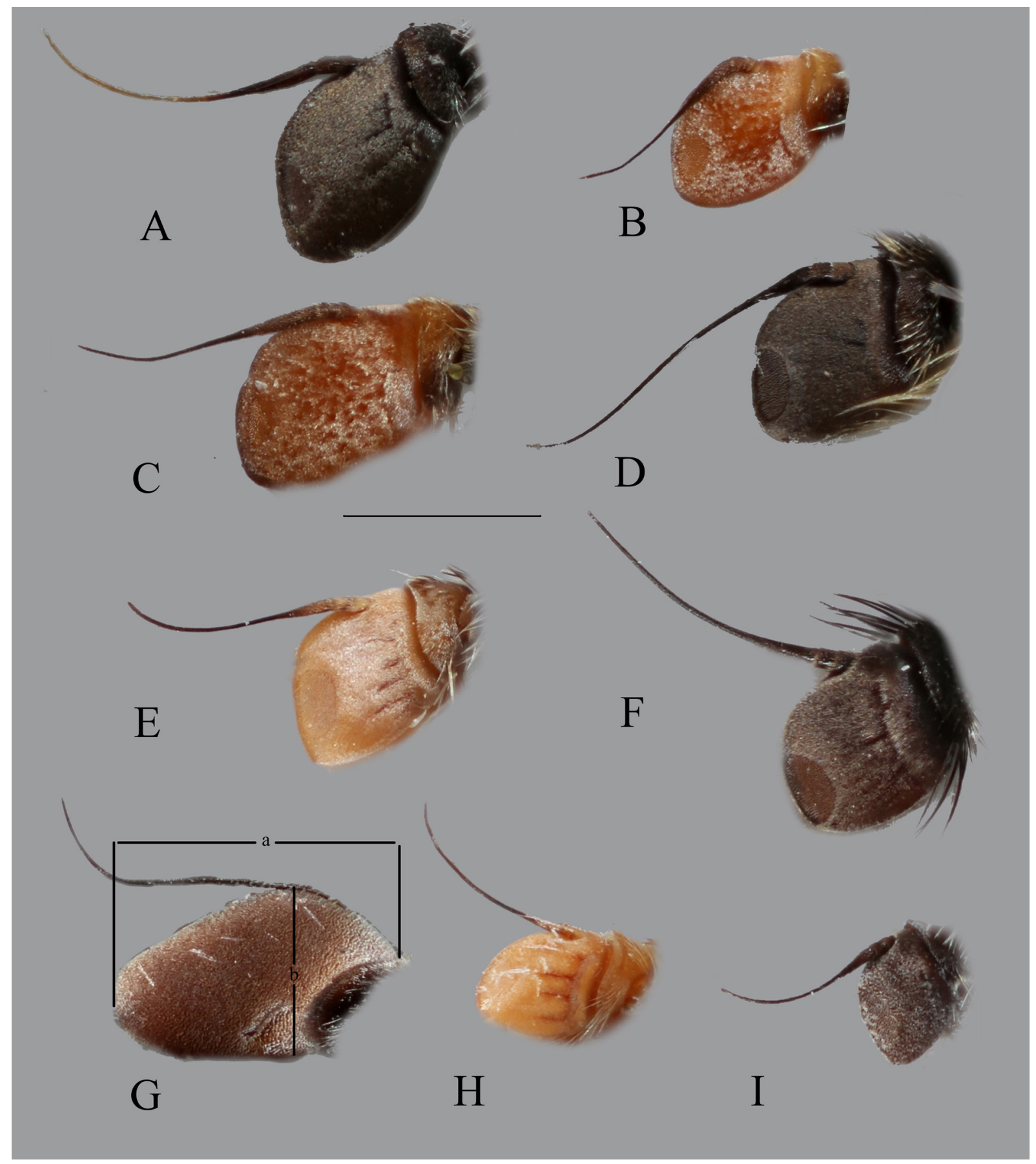

Fig. 11. Basoflagellomere, mediolateral view. A. Eumerus atricolorus Gilasian \& van Steenis sp. nov., holotype, ठ (HMIM). B. E. brevipilosus Gilasian \& van Steenis sp. nov., holotype, § (HMIM). C. E. brevipilosus Gilasian \& van Steenis sp. nov., paratype, o (HMIM). D. E. chekabicus Gilasian \& van Steenis sp. nov., holotype, ô (HMIM). E. E. kazanovzkyae Paramonov, 1927, đ̂, Paveh, Iran (HMIM). F. E. hissaricus Stackelberg, 1949, ô, Ghoochan, Iran (HMIM). G. E. ovoformus Gilasian \& van Steenis sp. nov., holotype, ô (HMIM). H. E. pilosipedes Gilasian \& van Steenis sp. nov., holotype, $\widehat{\partial}$ (HMIM). I. E. vallicolus Gilasian \& van Steenis sp. nov., holotype, $\widehat{\partial}$ (HMIM). Scale bars $=0.5 \mathrm{~mm}$. Abbreviations: $a=$ length of basoflagellomere; $b=$ width of basoflagellomere. 


\section{Remarks}

The pile colour of the face varies among the three males collected from the same locality (Haftad-Qolleh Protected Area), of which two have black and one has white pile on the face. The genitalic characters of the three differ to some extent and fail to correspond with the colour of facial pile for a certain definition of the species. We have currently concluded that the differences in the colour of the facial pile likely resulted from intraspecific variations and decided to treat them as members of E. longitarsis. Further collecting from this area has been planned to study the range of the variations in the populations to see whether or not they are identical species.

Eumerus ovoformus Gilasian \& van Steenis, sp. nov. urn:lsid:zoobank.org:act:5BB1734C-B0D1-4883-B226-D5F83D263219

Figs 4C, 7C, 9F, 11G, 16E-F, 18E, 20E, 22E

\section{Diagnosis}

Basoflagellomere brownish-orange and egg-shaped; eyes long pilose, not coalescent; abdomen mostly red except for median black vitta on abdominal tergum II and median small black macula on anterior margin of tergum III. This species is closely related to E. coeruleus except for the following characters: eyes 8-9 ommatidia spaced (separated in E. coeruleus by about 4 ommatidia); ocellar triangle isosceles (equilateral in E. coeruleus); ocellar triangle 1.2 (0.6 in E. coeruleus) times as long as vertical triangle; distance between posterior ocelli to posterior margin of eye about 0.9 (1.2 in E. coeruleus) times as long as ocellar triangle; vertex wider than in E. coeruleus; head in dorsal view 3.5 times as wide as vertex at posterior corner of eyes (about 5.5 times in E. coeruleus); vein $\mathrm{R}_{4+5}$ slightly sinuate (deeply sinuate in E. coeruleus); legs predominantly black except for orange apex of femora and orange basal third of tibiae (orange basal half of tibiae and almost entirely orange tarsi in E. coeruleus); metafemur more enlarged than in E. coeruleus; abdominal tergum III almost entirely orange (with distinct median black vitta in E. coeruleus); posterior lobe of surstylus (dorsal view) truncated apically on outer side (uniformly rounded in E. coeruleus); posterior lobe of surstylus (dorsal view) with a distinct process on inner side (without process in E. coeruleus).

\section{Etymology}

The specific epithet 'ovoformus' [Latin] is derived from 'ovum' (egg) and 'forma' (shape), in reference to the egg-shaped basoflagellomere which is very characteristic for this species within the genus Eumerus.

\section{Material examined}

\section{Holotype}

IRAN - O'; "IRAN: Markazi prov., Haftad / Qolleh Protected Area, / Chekab Valley, 2219 m, / $34^{\circ} 07^{\prime} 0.5^{\prime \prime} \mathrm{N}, 050^{\circ} 16^{\prime} 25.3^{\prime \prime} \mathrm{E}, / 25 . \mathrm{v}-15 . v i .2016$, Malaise trap / near pool, E. Gilasian \& M. / ParchamiAraghi // HOLOTYPUS ô / Eumerus ovoformus / Gilasian \& van Steenis / 2020 [red label]"; HMIM.

\section{Description}

Male (Figs 4C, 7C)

MEASUREMENTS. Body length: $7.5 \mathrm{~mm}$; wing length: $6.2 \mathrm{~mm}$.

HEAD (Fig. 16E-F). Eyes long pilose, dichoptic, 8-9 ommatidia spaced; face nearly parallel-sided, weakly grey pollinose and covered with long whitish pile; frontal triangle predominantly shiny black, weakly grey pollinose at lateral margin and with whitish pile; head in frontal view about 3.5 times as wide as face; frontal triangle about 1.3 times as long as vertical triangle; vertical triangle shiny black, with whitish pile; ocellar triangle isosceles; ocellar triangle shiny black, with whitish pile, almost 


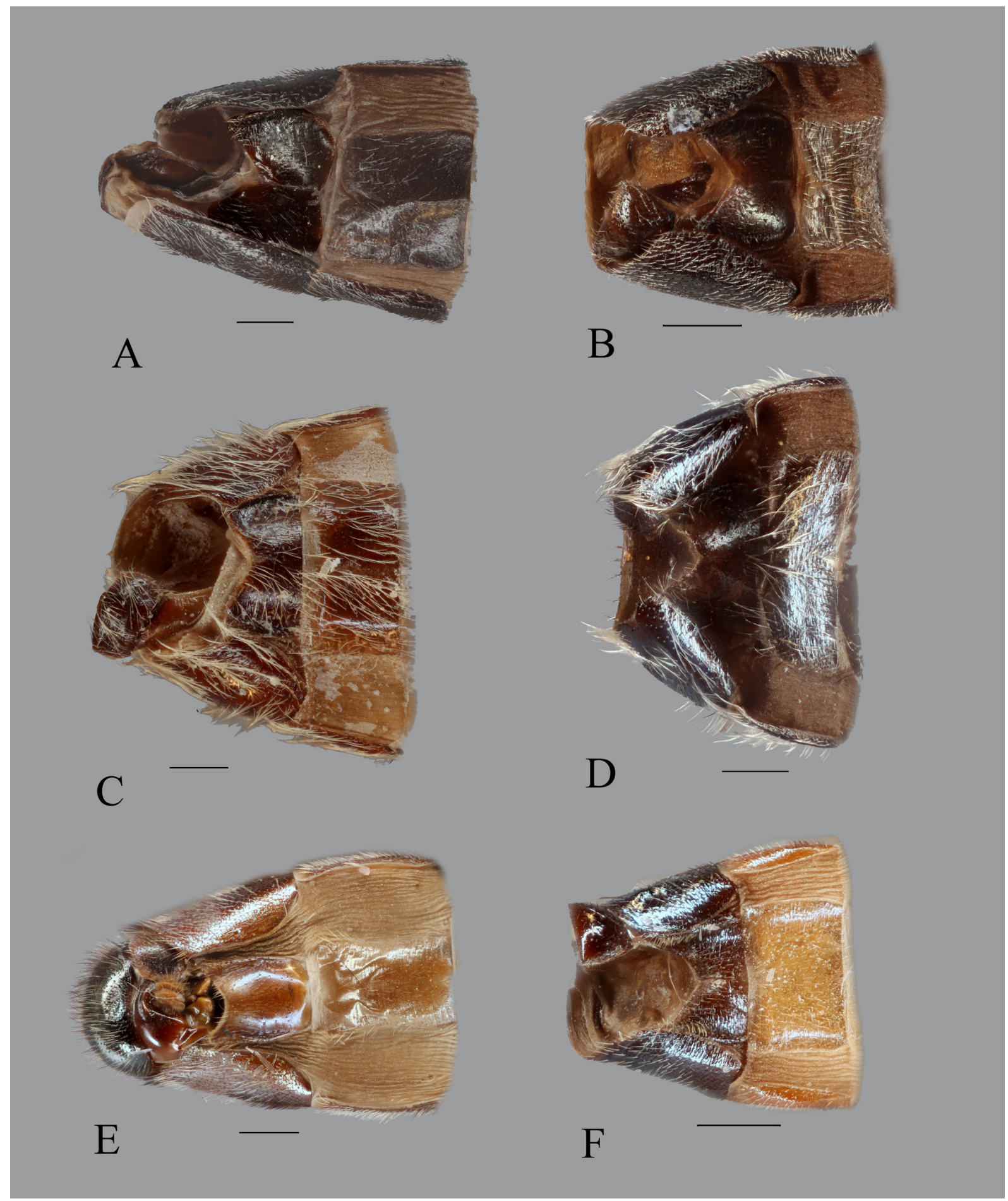

Fig. 12. Sternum IV, Ô, ventral view. A. Eumerus atricolorus Gilasian \& van Steenis sp. nov., holotype (HMIM). B. E. brevipilosus Gilasian \& van Steenis sp. nov., holotype (HMIM). C. E. chekabicus Gilasian \& van Steenis sp. nov., holotype (HMIM). D. E. hissaricus Stackelberg, 1949, Ghoochan, Iran (HMIM). E. E. pilosipedes Gilasian \& van Steenis sp. nov., holotype (HMIM). F. E. vallicolus Gilasian \& van Steenis sp. nov., holotype (HMIM). Scale bars $=0.5 \mathrm{~mm}$. 
1.15 times as long as wide and about 1.2 times as long as vertical triangle; distance between posterior ocelli to posterior margin of eye about 0.9 times as long as ocellar triangle; occiput grey pollinose, with light pile; frontal triangle nearly 1.5 times as wide as ocellar triangle; vertex at posterior corner of eyes 1.6 times as wide as vertex over posterior ocelli; head in dorsal view 3.5 times as wide as vertex at posterior corner of eyes; scape and pedicel dark brown; basoflagellomere brownish-orange, egg-shaped, 1.7 times as long as wide; arista brown, 1.1 times as long as basoflagellomere (Fig. 11G).

THORAX. Scutum and scutellum shiny black with long yellowish-white pile; scutellum with marginal rim; pleurae shiny black, covered with long yellowish pile except for bare meron and katepimeron; metasternum pilose.

Legs (Fig. 9F). Predominantly shiny black except for orange apex of femora and orange basal third of tibiae; proleg predominantly with white pile except for a little black pile on basal half of profemur ventrally; mesoleg mostly with white pile except for black pilosity on mesofemur anteriorly; metaleg mostly with long whitish pile with exception of a little black pile on metafemur apicoventrally, short black pile on metatibia ventrally and a short tuft of orange pile on metatarsus ventrally; metafemur simple, enlarged, about 3.2 times as long as wide, ventral pile about $1 / 3$ of width of metafemur; anteroventral and posteroventral margins of metafemur each with a row of 7 respectively 3 black setae apically.

WING. Hyaline; entirely microtrichose; vein $\mathrm{R}_{4+5}$ slightly sinuate; calypters whitish; halter yellowish-white.

ABDOMEN. Tergum I black with whitish pile laterally; terga II-IV each with a pair of lunulate-shaped oblique maculae of white pollinosity; tergum II orange with a median black 'pewter chalice'-shaped vitta; tergum II mostly white pilose except for black pilosity on about posterior third, anterolateral pile on tergum II long; terga III-IV predominantly orange, tergum III with a median small black macula on anterior margin; pile on tergum III short and black dorsally, white and long laterally; tergum IV pilosity mostly white, except for short black pile anteriorly; sterna yellowish pilose; sternum I black; sterna IIIV orange; sternum IV rectangular, with median V-shaped incision posteriorly.

Genitalia (Figs 18E, 20E, 22E). Hypandrium simple; aedeagal apodeme as in Fig. 22E in lateral view; cercus semi-rectangular; posterior lobe of surstylus (lateral view) wide, with only long median setae, without a row of short setulae posteriorly; posterior lobe of surstylus (dorsal view) narrowed toward apex, truncated apically on outer side and with a distinct process on inner side; inner accessory lobe of surstylus with short pile.

\section{Female}

Unknown.

\section{Distribution}

Iran.

Eumerus persarum Stackelberg, 1961

Figs 4D, 5D, 7D, 8D, 14G-H, 16G-H

\section{Diagnosis}

Eyes pilose (Figs 14G-H, 16H), males holoptic (Fig. 16G); face white pilose; basoflagellomere orange (Figs $14 \mathrm{H}, 16 \mathrm{H}$ ); scutum and scutellum shiny metallic, weakly pollinose, covered with whitish pile (Figs 4D, 5D, 7D, 8D); subscutellar pile fringe long and dense and with apices strongly bent medially; pleura above metacoxa pilose; legs predominantly black; metafemur enlarged; protarsus with strong setae along posterior margin, especially basitarsomere with several setae along entire posterior margin; wing extensively bare of microtrichia, also on apical half; abdomen brownish-orange (Figs 4D, 5D). 


\section{Material examined}

\section{Holotype}

IRAN • + ; “ Bempur Baluch. / Iran. 11.X.955 / Tsjerbinovsky // Eumerus Holotyp. / persarum, sp. n. '61 / Stackelberg det. // Holotypus '60 / Eumerus / persarum Stack [red label]”; ZISP.

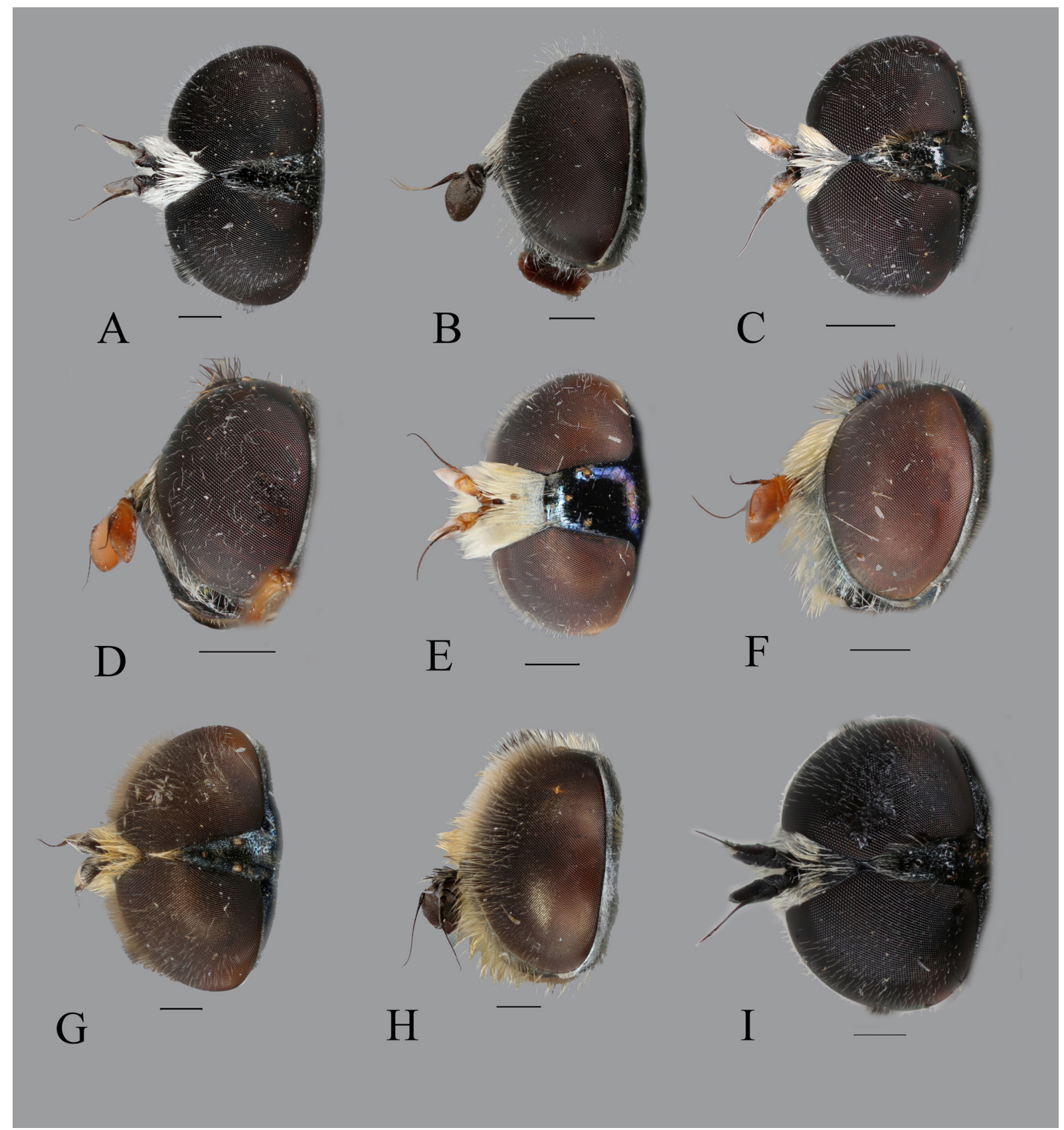

Fig. 13. Head, Ô, dorsal view (A, C, E, G, I) and lateral view (B, D, F, H). A-B. Eumerus atricolorus Gilasian \& van Steenis sp. nov., holotype (HMIM). C-D. E. brevipilosus Gilasian \& van Steenis sp. nov., holotype (HMIM). E-F. E. falsus Becker, 1922, Chekab Valley, Iran (HMIM). G-H. E. chekabicus Gilasian \& van Steenis sp. nov., holotype (HMIM). I. E. tricolor (Fabricius, 1798), Paleochori, Greece (JSA). Scale bars $=0.5 \mathrm{~mm}$. 


\section{Other material}

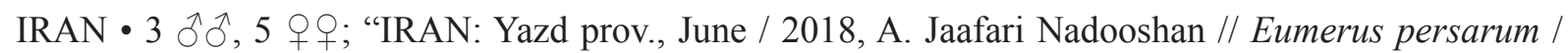
Stackelberg, 1961 // reared on Cistanche sp."; HMIM • 1 §ं; same collection data as for preceding; JSA • 1 q; "SE Iran / Bazman / 13.4.73 // Loc. no 161 / Exp. Nat. Mus. / Praha”; JSA.

\section{Distribution}

Iran (Sistan \& Balouchestan prov., Bampur; Yazd prov.) (Peck 1988).

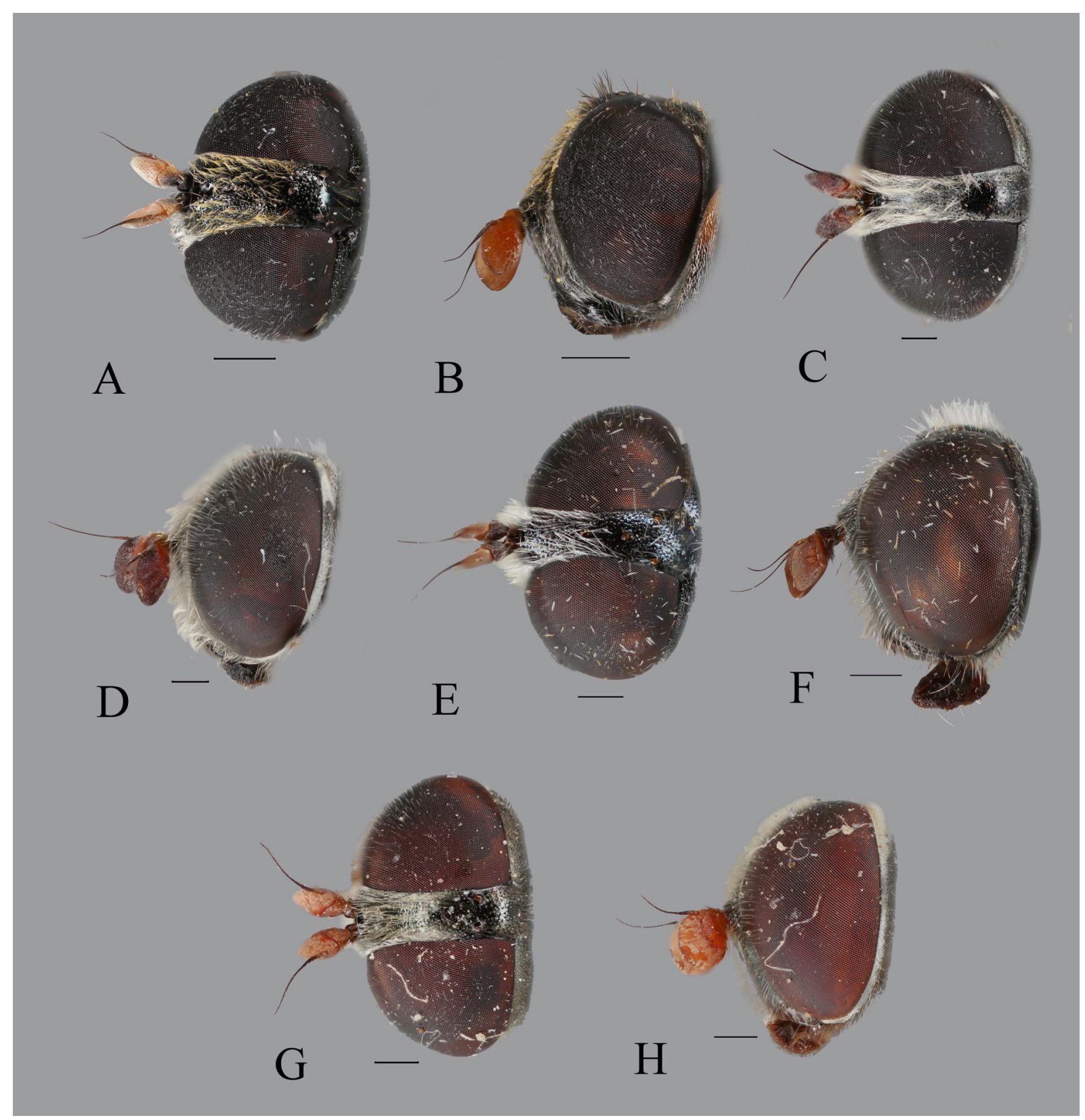

Fig. 14. Head, $q$, dorsal view (A, C, E, G) and lateral view (B, D, F, H). A-B. Eumerus brevipilosus Gilasian \& van Steenis sp. nov., paratype (HMIM). C-D. E. coeruleus (Becker, 1913), Ghoochan, Iran (HMIM). E-F. E. longitarsis Peck, 1979, Mian Jangal, Iran (JSA). G-H. E. persarum Stackelberg, 1961, Bazman, Iran (JSA). Scale bars $=0.5 \mathrm{~mm}$. 
Eumerus persicus Stackelberg, 1949

Diagnosis (based on Stackelberg 1961)

\section{Female}

Eyes almost bare; face and frontal triangle shiny black, without polinosity; antennae reddish-orange, basoflagellomere oval; scutum and scutellum shiny black, without median pollinose vittae; metafemur distinctly enlarged, mostly orange with exception of black apex; metatibia black; wing hyaline; abdomen predominantly orange.

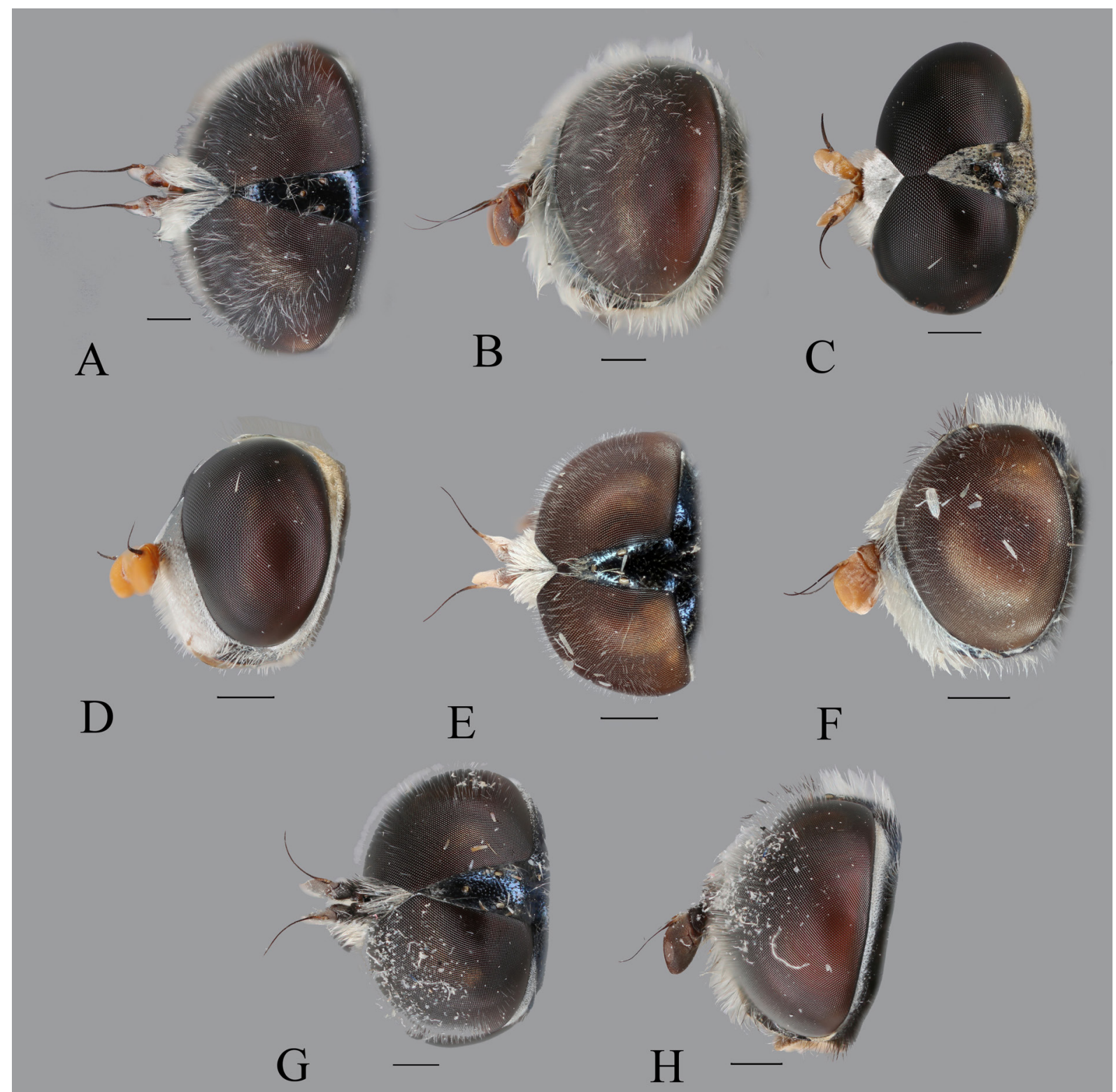

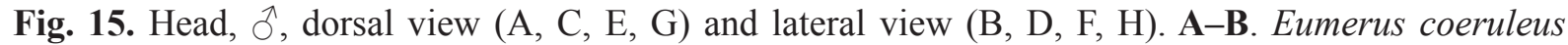
(Becker, 1913), Chekab Valley, Iran (JSA). C-D. E. jacobsoni Becker, 1913, Chekab Valley, Iran (JSA). E-F. E. kazanovzkyae Paramonov, 1927, Paveh, Iran (HMIM). G-H. E. longitarsis Peck, 1979, Chekab Valley, Iran (JSA). Scale bars $=0.5 \mathrm{~mm}$. 


\section{Male}

Unknown.

\section{Material examined}

We had no access to any specimen of this species, which was originally described and is exclusively known from Iran (type locality: Tehran prov., Damavand).

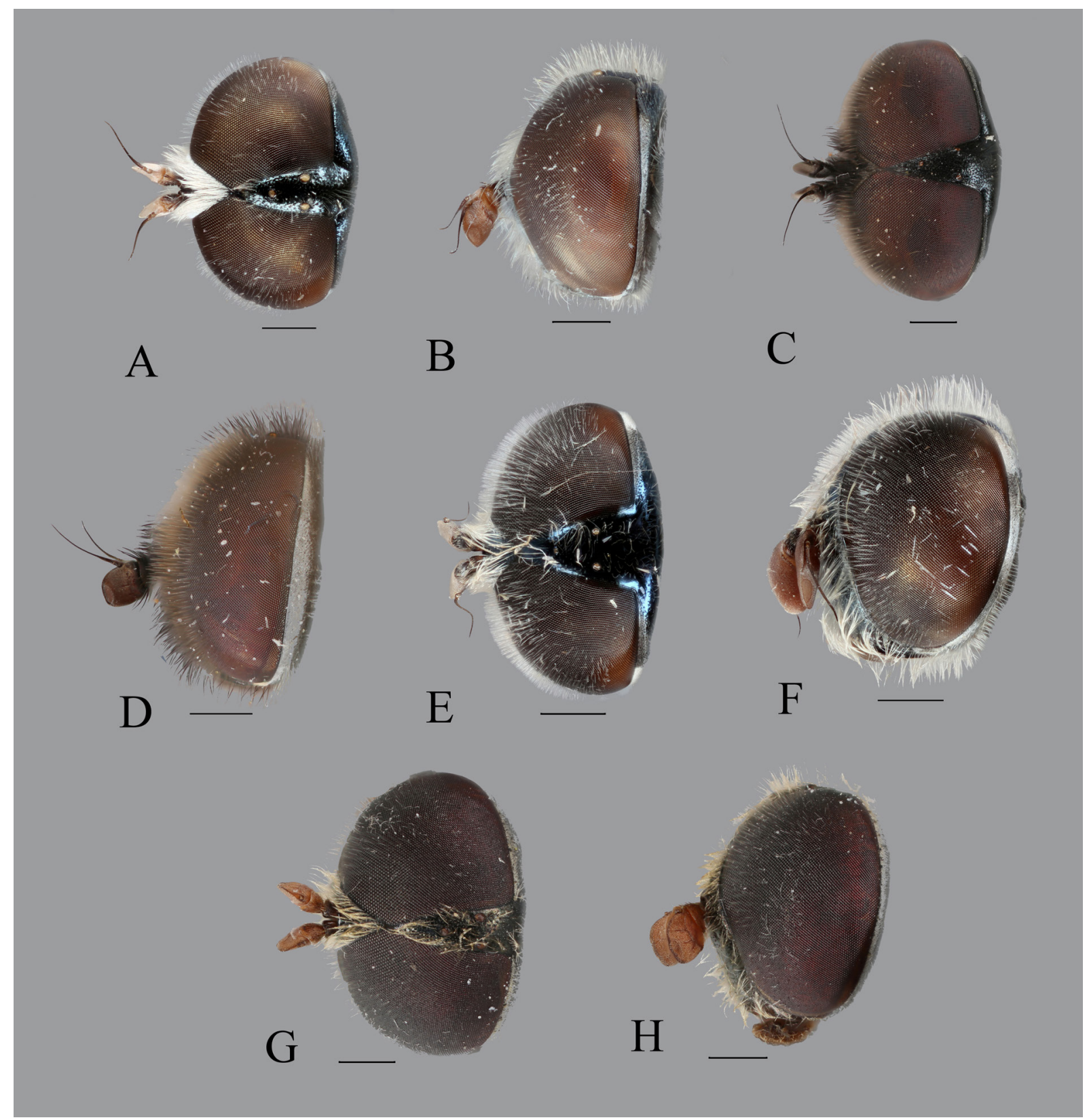

Fig. 16. Head, $\widehat{\partial}$, dorsal view (A, C, E, G) and lateral view (B, D, F, H). A-B. Eumerus sp., Khash, Iran (HMIM). C-D. E. hissaricus Stackelberg, 1949, Ghoochan, Iran (HMIM). E-F. E. ovoformus Gilasian \& van Steenis sp. nov., holotype (HMIM). G-H. E. persarum Stackelberg, 1961, Yazd, Iran (JSA). Scale bars $=0.5 \mathrm{~mm}$. 


\section{Remarks}

We failed to collect any specimens of this species during this study and our attempts to access the type material were not fruitful. Based on its diagnostic characters, original description (Stackelberg 1949) and the identification key (Stackelberg 1961), this species is readily separated from other Iranian species studied through this research.

\section{Distribution}

Iran (Peck 1988).

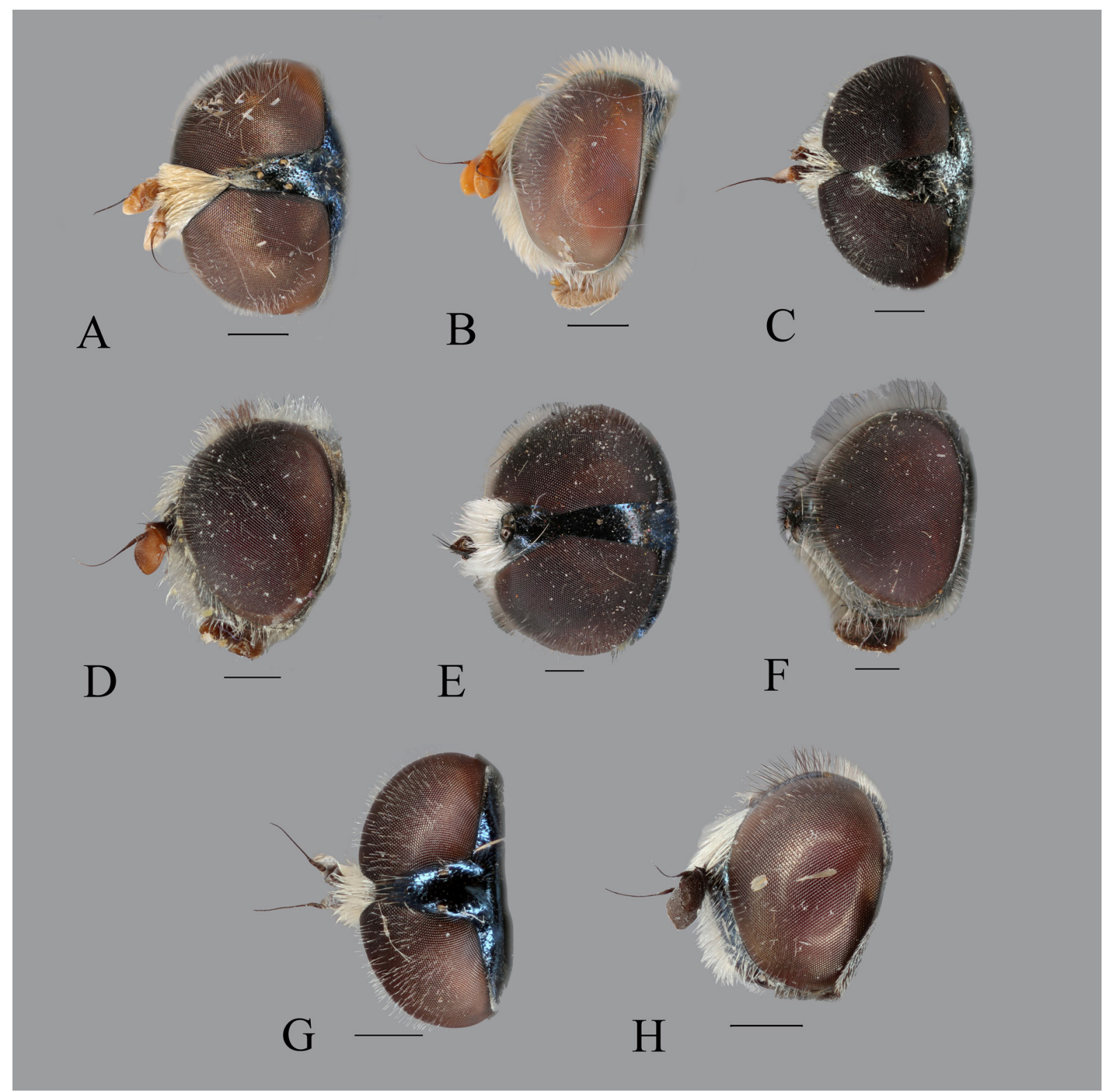

Fig. 17. Head, Ô, dorsal view (A, C, E, G) and lateral view (B, D, F, H). A-B. Eumerus pilosipedes Gilasian \& van Steenis sp. nov., holotype (HMIM). C-D. E. richteri Stackelberg, 1960, Lar, Iran (HMIM). E-F. E. tadzhikorum Stackelberg, 1949, Chekab Valley, Iran (JSA). G-H. E. vallicolous Gilasian \& van Steenis sp. nov., holotype (HMIM). Scale bars $=0.5 \mathrm{~mm}$. 
Eumerus pilosipedes Gilasian \& van Steenis sp. nov. urn:Isid:zoobank.org:act:249E4D1F-6FCE-4574-A63E-B4A909F18059

Figs 4E, 7E, 10B-C, 11H, 12E, 17A-B, 19C, 21C, 23C

\section{Diagnosis}

This species is closely related to E. kazanovzkyae except for the following characters: eyes more widely separated, nearly 3-4 ommatidia spaced (separated in E. kazanovzkyae by about 1 ommatidium); frontal triangle about 2.0-2.3 (1.75 in E. kazanovzkyae) times as long as vertical triangle; scutum and pleurae with longer pile; metafemur with longer ventral pile, about $1 / 4-1 / 3(1 / 8-1 / 7$ in E. kazanovzkyae) width of metafemur; dense thick pile fringe on apicodorsal part of metatibia almost absent (long pile fringe about $3 / 5$ width of metatibia present); metatarsus with pile fringe on entire dorsal surface (with narrower pile fringe in E. kazanovzkyae that is confined to antero-dorsal margin of metatarsus); wing slightly infuscated in apical half from anterior margin to anterior half of cell $\mathrm{dm}$ (strongly infuscated in E. kazanovzkyae reaching to posterior margin of wing); posterior lobe of surstylus in dorsal view uniformly rounded apically and entirely covered with setulae (truncated on inner side in E. kazanovzkyae with scattered setulae).

\section{Etymology}

The specific epithet 'pilosipedes' is derived from 'pile' (pile) and 'pedes' (foot), in reference to the thick pilose metatarsus.

\section{Material examined}

\section{Holotype}

IRAN - O'; "IRAN: Markazi prov., Haftad / Qolleh Protected Area, / Chekab Valley, 2219 m, / $34^{\circ} 07^{\prime} 0.5^{\prime \prime} \mathrm{N}, 050^{\circ} 16^{\prime} 25.3^{\prime \prime} \mathrm{E}, / 25 . \mathrm{v}-15 . v i .2016$, Malaise trap / near pool, E. Gilasian \& M. / ParchamiAraghi // HOLOTYPUS $\widehat{\jmath}$ / Eumerus pilosipedes / Gilasian \& van Steenis / 2020 [red label]”; HMIM.

\section{Paratypes}

IRAN $\bullet 6 \hat{\jmath}$; same collection data as for holotype; HMIM.

\section{Description}

Male (Figs 4E, 7E)

MeAsurements. Body length: 6.8-9.7 mm; wing length: 5-6.9 mm.

HEAD (Fig. 17A-B). Eyes pilose, dichoptic, nearly 3-4 ommatidia spaced; face nearly parallel-sided, grey pollinose and covered with dense and long yellowish-white pile; frontal triangle grey pollinose, entirely covered with dense golden pile; head in frontal view about 3.30-3.35 times as wide as face; frontal triangle about 2.0-2.3 times as long as vertical triangle; vertical triangle whitish grey pollinose, with yellowish pile; ocellar triangle isosceles; ocellar triangle shiny black, with yellowish pile, 1.101.15 times as long as wide and 1.4 times as long as vertical triangle; distance between posterior ocelli to posterior margin of eye nearly as long as ocellar triangle; occiput light grey pollinose, with light pile; frontal triangle nearly 2 times as wide as ocellar triangle; vertex at posterior corner of eyes 1.4 times as wide as vertex over posterior ocelli; head in dorsal view 4.5 times as wide as vertex at posterior corner of eyes; antennae yellowish-orange, arista mostly dark brown except for yellowish basal aristomeres; basoflagellomere more or less rounded apically, 1.0-1.2 times as long as wide; arista 1.7-2 times as long as basoflagellomere (Fig. 11H).

THORAX. Scutum and scutellum shiny black with long yellowish pile; scutum with two narrow median pollinose vittae reaching to $1 / 3-1 / 2$ behind median suture and with two lateral weak pollinose vittae viewed 


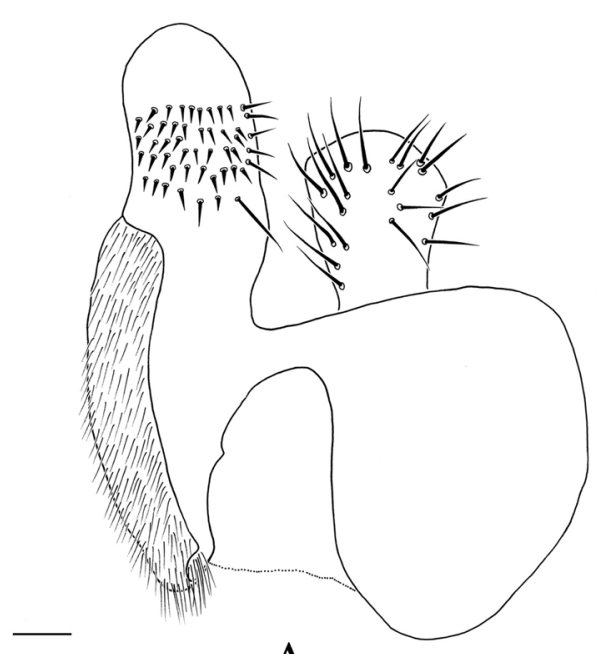

A
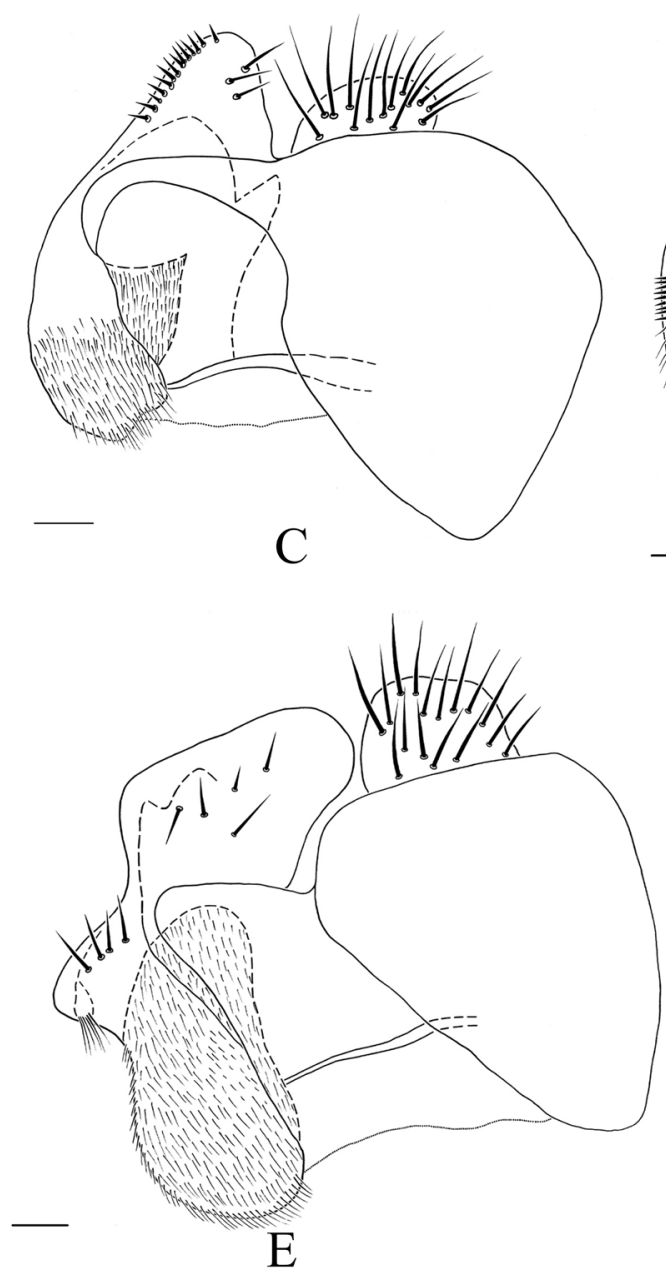

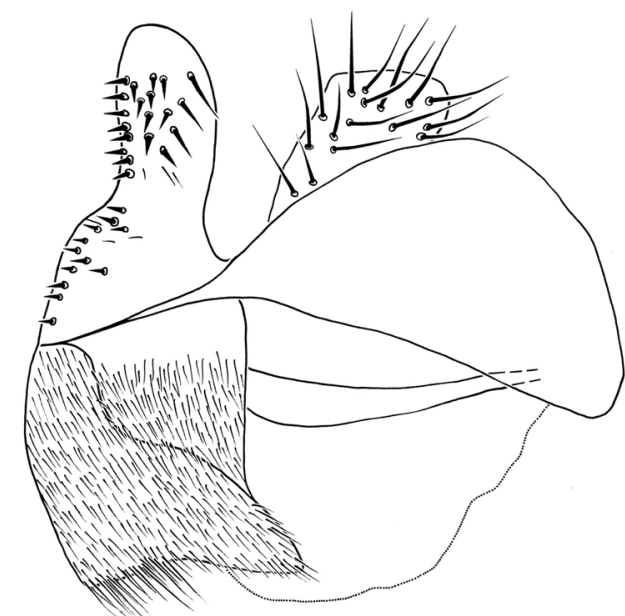

B
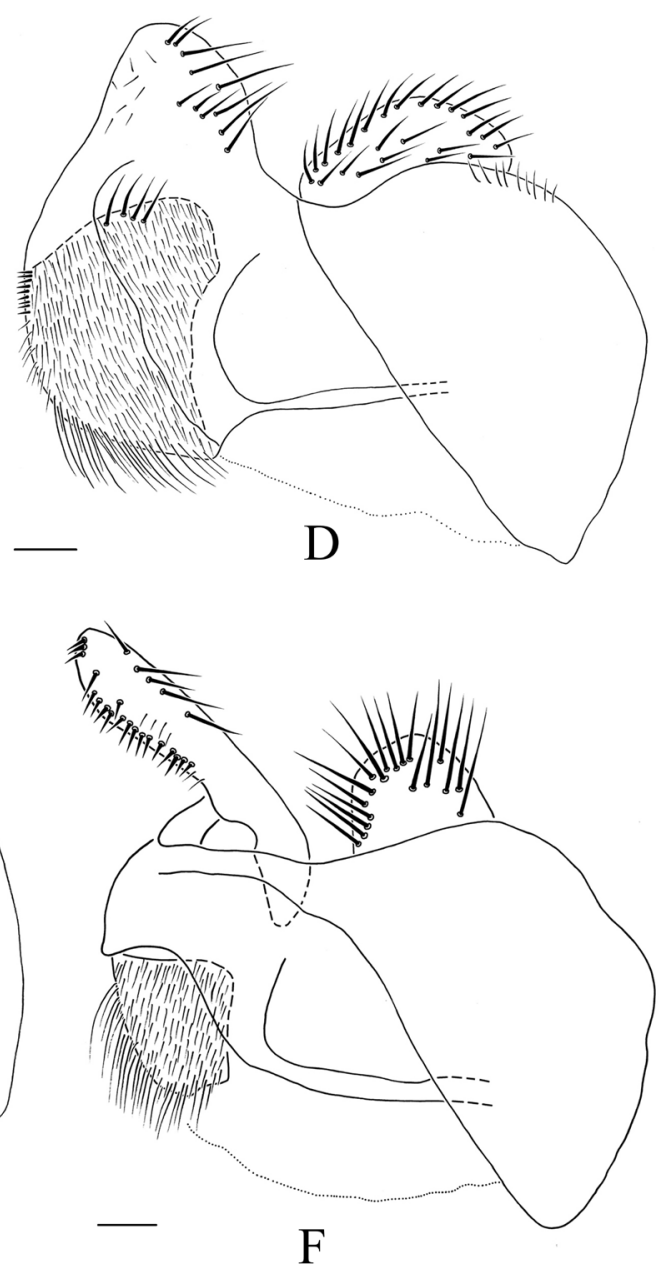

Fig. 18. Epandrium, cercus and surstylus, lateral view. A. Eumerus atricolorus Gilasian \& van Steenis sp. nov., holotype (HMIM). B. E. brevipilosus Gilasian \& van Steenis sp. nov., holotype (HMIM). C. E. chekabicus Gilasian \& van Steenis sp. nov., holotype (HMIM). D. E. coeruleus (Becker, 1913), Chekab Valley, Iran (HMIM). E. E. ovoformus Gilasian \& van Steenis sp. nov., holotype (HMIM). F. E. richteri Stackelberg, 1960, Lar, Iran (HMIM). Scale bars $=0.1 \mathrm{~mm}$. 


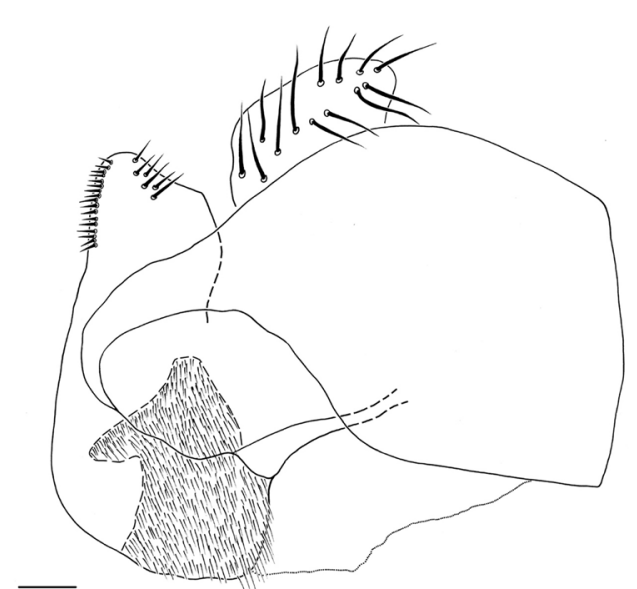

A

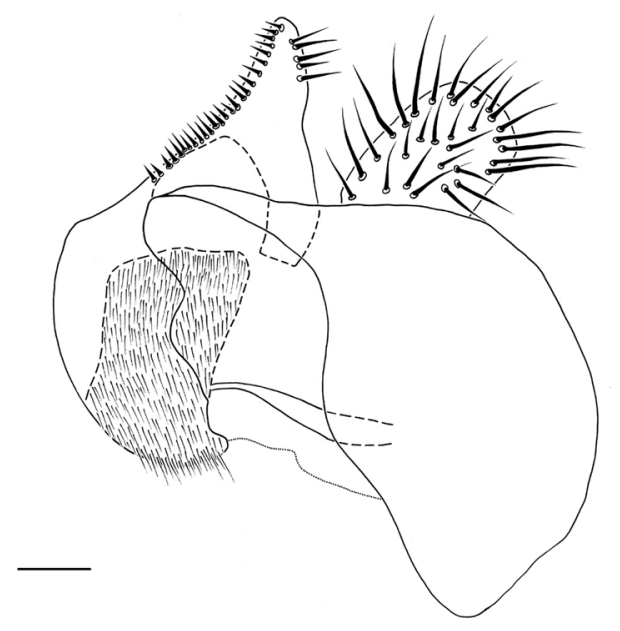

$\mathrm{C}$

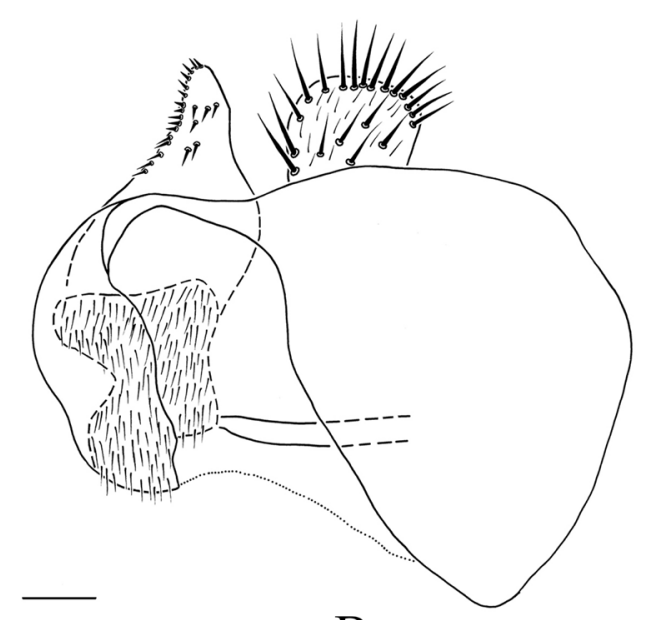

$\mathrm{B}$

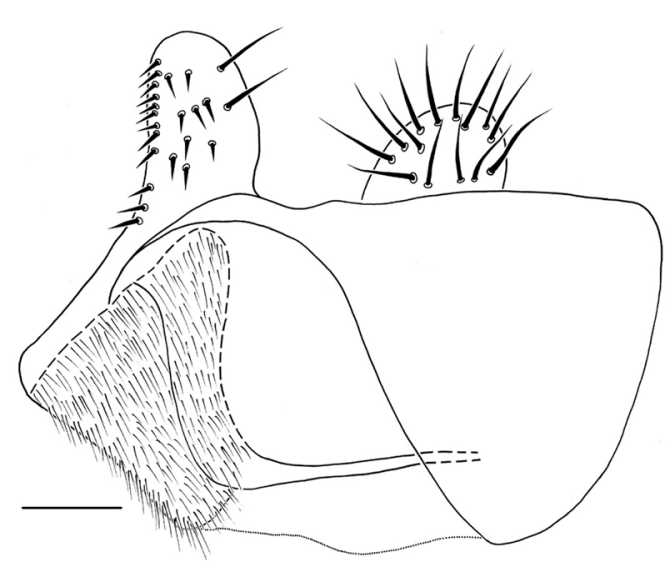

$\mathrm{D}$

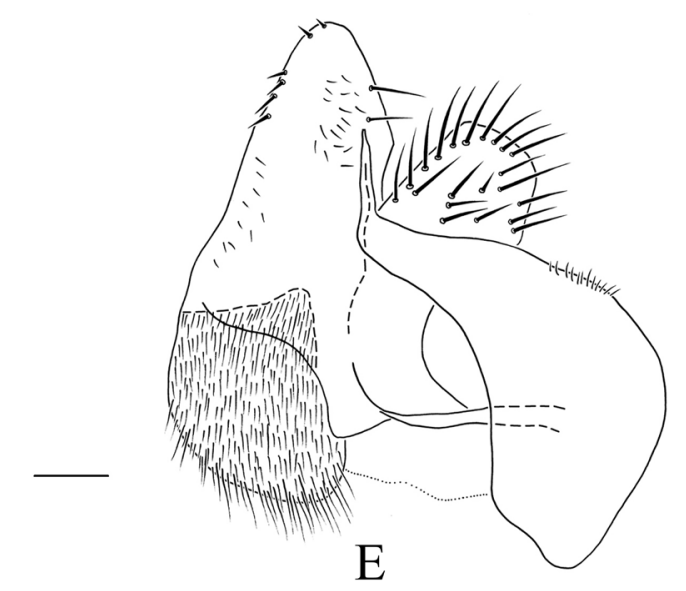

Fig. 19. Epandrium, cercus and surstylus, lateral view. A. Eumerus hissaricus Stackelberg, 1949, Ghoochan, Iran (HMIM). B. E. kazanovzkyae Paramonov, 1927, Paveh, Iran (HMIM). C. E. pilosipedes Gilasian \& van Steenis sp. nov., holotype (HMIM). D. E. vallicolus Gilasian \& van Steenis sp. nov., holotype (HMIM). E. Eumerus sp., Khash, Iran (HMIM). Scale bars $=0.1 \mathrm{~mm}$. 
dorsally; anterior part of median vittae semi-triangular; posterolateral part of scutum with a longitudinal row of setulae above base of wing; scutellum with marginal rim; pleurae black, weakly pollinose and covered with long yellowish pile except for bare anterior parts of anepisternum and katepisternum, meron and posterior part of anepimeron; metasternum pilose.

LEGS (Fig. 10B-C). Predominantly shiny black; apical tip of femora orange, pro- and mesofemora sometimes orange in apical $1 / 3-1 / 2$, metafemur rarely orange in apical $1 / 4-1 / 3$; basal half of pro- and mesotibia and basal third of metatibia orange; pro- and mesotarsus orange, connecting parts of tarsomeres black; metatarsus brownish-black; proleg with yellowish pile; mesoleg predominantly with yellowish pile except for black pilosity anteriorly; mesotibia and tarsomeres of mesotarsus with apical black setulae anteriorly; metacoxa with dense yellowish pile; metafemur simple, slightly enlarged, about 4 times as long as wide, with long yellowish pile ventrally, ventral pile $1 / 5-1 / 4$ of width of metafemur; anteroventral and posteroventral margins of metafemur each with a row of 10 respectively 6 black setae in about apical half; metatibia black pilose except for a little yellowish basal short pile dorsally; apicodorsal pile of metatibia about $1 / 3$ of width of metatibia; metatarsus with long black pile fringe which occupies entire dorsal surface of tarsomeres, other parts of metatarsus with brown pile.

WING. Wing entirely microtrichose, slightly infuscated in apical half from anterior margin to anterior half of cell dm, calypters yellowish; halter yellowish-orange.

ABDomen. Tergum I black with whitish pile laterally; terga II-IV each with a pair of lunulate-shaped oblique maculae of white pollinosity; tergum II orange with a median black 'pewter chalice'-shaped vitta; tergum II mostly white pilose except for black pilosity on about posterior third, anterolateral piles on tergum II dense and long; terga III-IV entirely orange with mostly black pile except for white pile on their oblique maculae; sterna yellowish short pilose; basal half of sternum I black; apical half of sternum I and sterna II-IV orange; sternum IV rectangular, with rounded posterolateral corners and with median wide incision posteriorly (Fig. 12E).

Genitalia (Figs 19C, 21C, 23C). Hypandrium simple; aedeagal apodeme as in Fig. 23C in lateral view; cercus semi-rectangular; posterior lobe of surstylus narrowed toward apex in lateral view and uniformly rounded apically in dorsal view, entirely covered with setulae dorsally; inner accessory lobe of surstylus with short pile.

\section{Female}

Unknown.

\section{Distribution}

Iran.

Eumerus richteri Stackelberg, 1960

Figs 4F, 7F, 17C-D, 18F, 20F, 22F

\section{Diagnosis}

Eyes pilose, coalescent in one point in males (Fig. 17C-D); face and frontal triangle white pilose; basoflagellomere orange (Fig. 17D); scutum and scutellum shiny metallic, weakly pollinose (Fig. 4F), covered with relatively long yellowish pile (Fig. 7F); legs predominantly black, tarsi and basal $1 / 2-1 / 3$ of tibiae orange; metafemur slightly enlarged; wing hyaline, almost entirely covered with microtrichia; abdomen brownish-black (Fig. 4F); male genitalia as in Figs 18F, 20F, 22F. 


\section{Material examined}

Holotype

AZERBAJDJAN • đ̊; “C. Ljaketag Culfa. / district, Nakhichev. ASSR / V. Richter 30.VI.959 // Eumerus Holotype / richteri, sp. n. '59 / Stackelberg det. // Holotypus '60 / Eumerus / richteri Stack [red label]”; ZISP.

\section{Other material}

IRAN • 1 ठ̊;; "IRAN, Tehran prov., / Lar, Emamzadeh / 2500 m, 13.viii, 1993 / M. Parchami-Araghi, E. Ebrahimi // Eumerus richteri / Stackelberg, 1960"; HMIM.

\section{Distribution}

Transcaucasia (Peck 1988). New record from Iran.

Eumerus tadzhikorum Stackelberg, 1949

Figs 4G, 7G, 17E-F

\section{Diagnosis}

Eyes pilose, widely spaced in males (Fig. 17E-F); face white pilose; basoflagellomere brownish-black; scutum and scutellum shiny metallic (Fig. 4G); scutum without median pollinose vittae and covered with long brownish pile (Fig. 7G); legs predominantly black, basal third of pro- and mesotibia, basal half of metatibia and apical half of metafemur orange; metaleg extremely long and slender; wing infuscated (Fig. 4G); abdominal terga II-IV predominantly reddish-orange (Fig. 7G).

\section{Material examined}

\section{Lectotype}

TADJIKISTAN • ○'; “Eiddy: S. skl. Gis- / sarask. chr., Tadj. / Stackelberg 16.VI.44 // Eumerus typ. '46 / tadzhikorum sp.n. / Stackleberg det. // Holotypus '49 / Eumerus / tadzhikorum Stack. [red label] // Lectotypus Eumerus /Fhissar tadzhikorum Stack / design. V. Richter [red label]”; ZISP.

\section{Other material}

KAZAKHSTAN・ 1 ठ̊; “Zapov. Aksu- / Jabagly / 24.V.1966 / L. Zimina”; ZMSU.

IRAN - 1 ô; "IRAN: Golestan prov., / P.M. Golestan, Almeh,/ 1700 m, 25.vii.2001/ E. Gilasian, M. Moghadam \& R. Ghayourfar // Eumerus tadzhikorum / Stackelberg, 1949"; HMIM • 1 ö; "IRAN: Khorasan prov., Ghoochan / Emamgholi, Chovinli / 37²5'44.1"N, 058 31'57.3"E, / 1746 m.; 30.v.2006

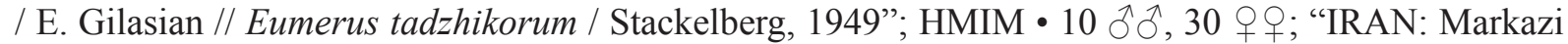
prov., Haftad / Qolleh Protected Area, / Chekab Valley, 2219 m, / 3407'0.5'N , 050 16'25.3"E, / Malaise trap, 30 May-3 June / 2017, E. Gilasian \& M. / Parchami-Araghi // Eumerus tadzhikorum / Stackelberg,

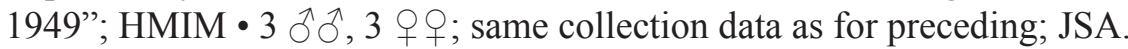

\section{Distribution}

Central Asia, Iran (Kordestan, Golestan, Khorasan and Markazi provinces) (Peck 1988; Barkalov \& Gharali 2004; Gilasian \& Barkalov 2004; Kamangar et al. 2004).

\section{Eumerus tricolor (Fabricius, 1798)}

Figs 8E, 13I

Syrphus tricolor Fabricius, 1798: 563. 


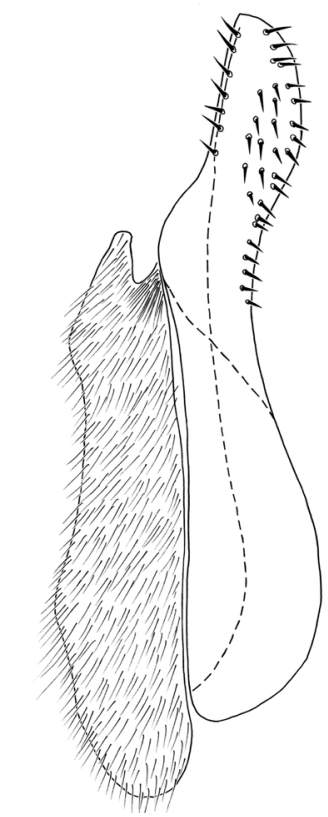

A

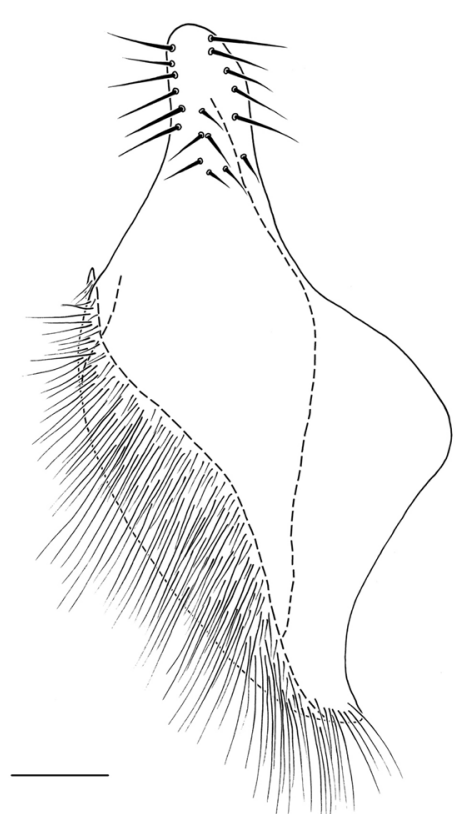

$\mathrm{D}$

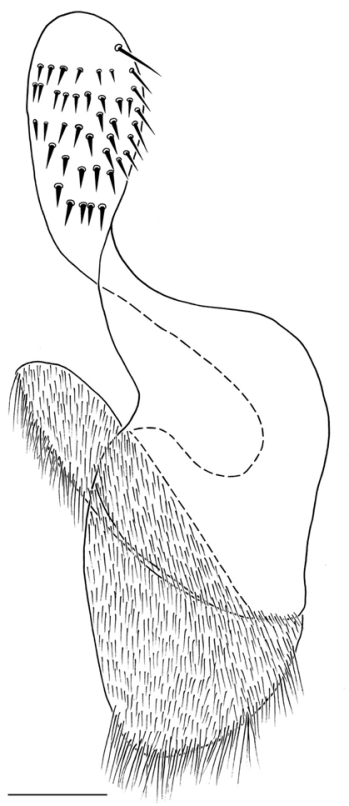

$\mathrm{B}$

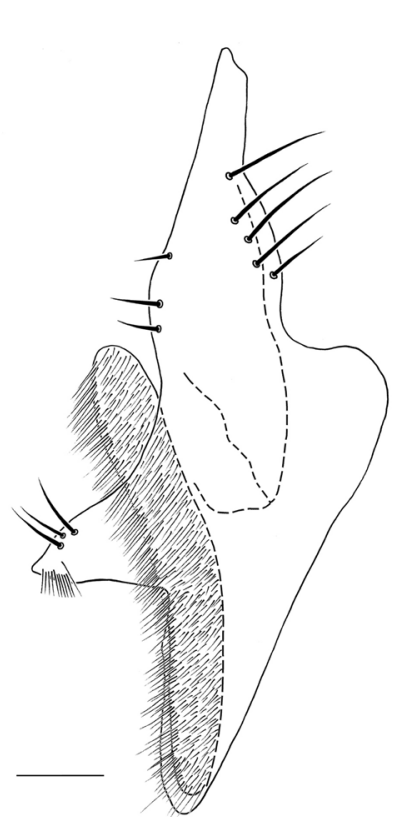

$\mathrm{E}$

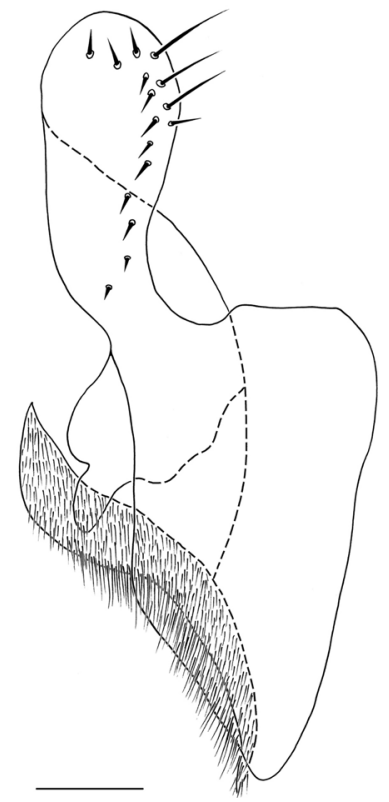

$\mathrm{C}$

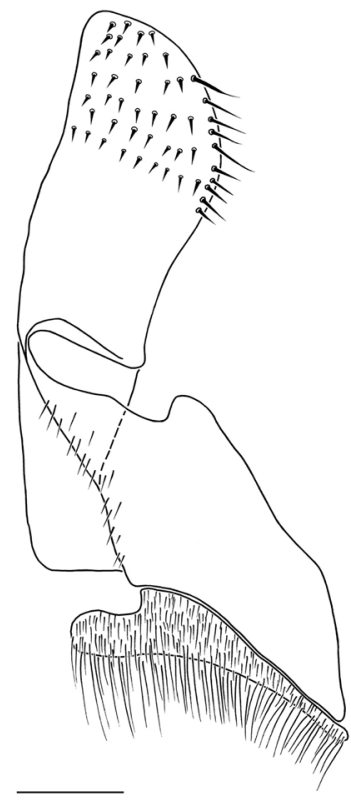

F

Fig. 20. Right surstylus, dorsal view. A. Eumerus atricolorus Gilasian \& van Steenis sp. nov., holotype (HMIM). B. E. brevipilosus Gilasian \& van Steenis sp. nov., holotype (HMIM). C. E. chekabicus Gilasian \& van Steenis. sp. nov., holotype (HMIM). D. E. coeruleus (Becker, 1913), Chekab Valley, Iran (HMIM). E. E. ovoformus Gilasian \& van Steenis sp. nov., holotype (HMIM). F. E. richteri Stackelberg, 1960, Lar, Iran (HMIM). Scale bars $=0.1 \mathrm{~mm}$. 


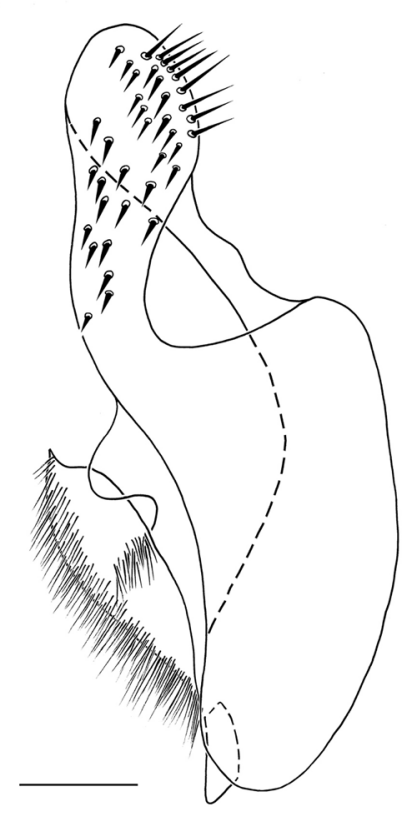

A

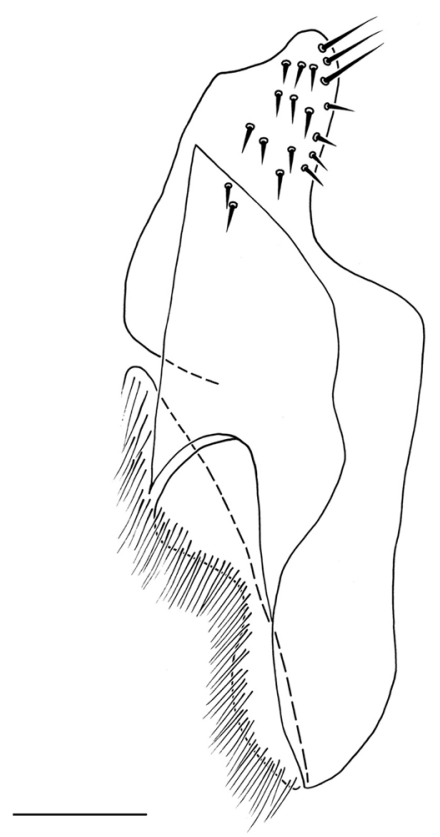

B

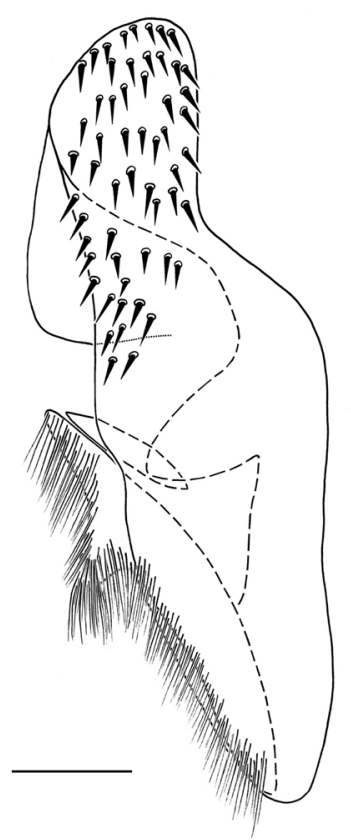

$\mathrm{C}$

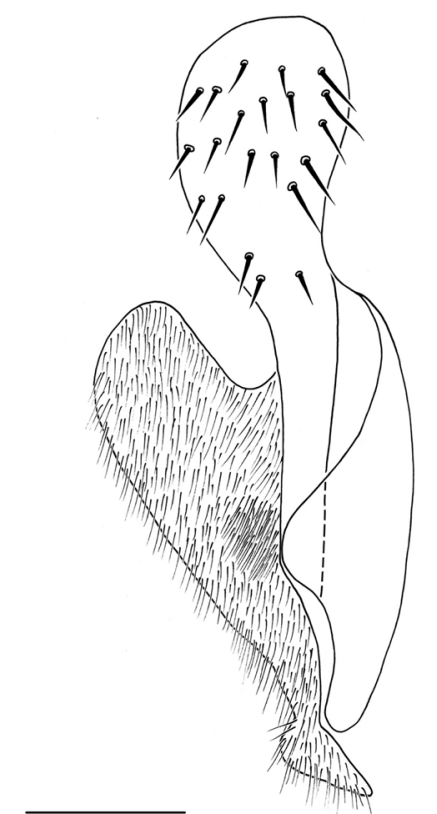

$\mathrm{D}$

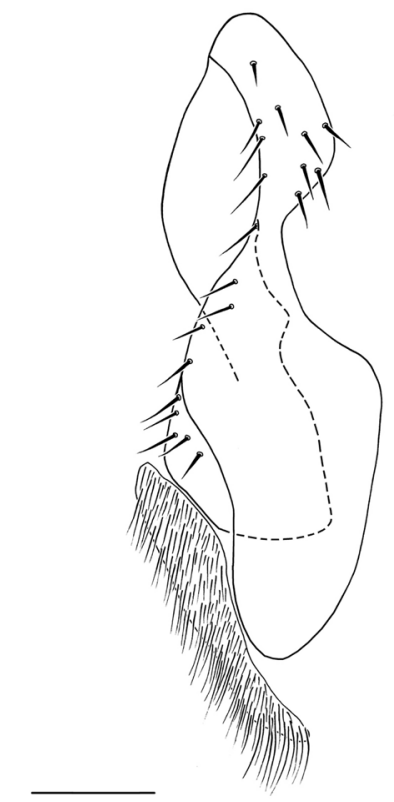

$\mathrm{E}$

Fig. 21. Right surstylus, dorsal view. A. Eumerus hissaricus Stackelberg, 1949, Ghoochan, Iran (HMIM). B. E. kazanovzkyae Paramonov, 1927, Paveh, Iran (HMIM). C. E. pilosipedes Gilasian \& van Steenis sp. nov., holotype (HMIM). D. E. vallicolus Gilasian \& van Steenis sp. nov., holotype (HMIM). E. Eumerus sp., Khash, Iran (HMIM). Scale bars $=0.1 \mathrm{~mm}$. 


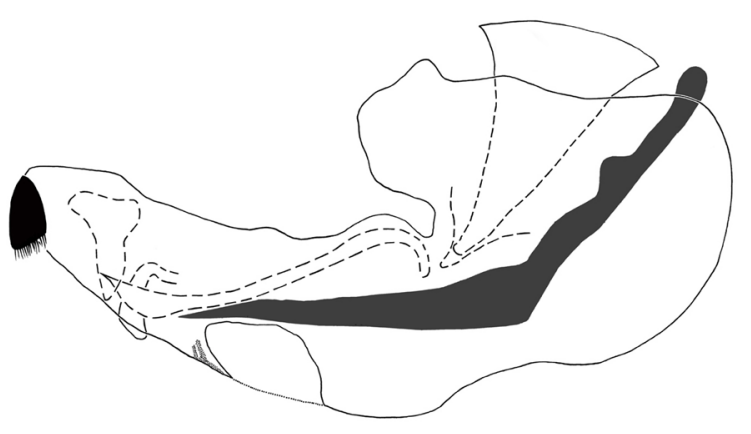

A

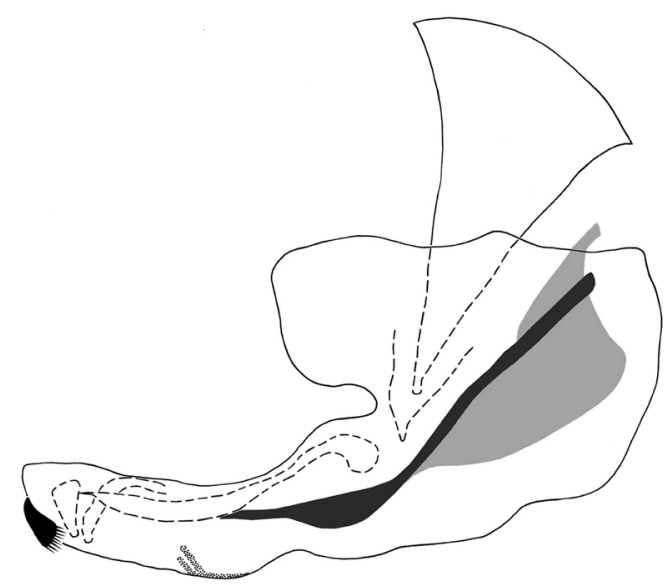

$\mathrm{C}$

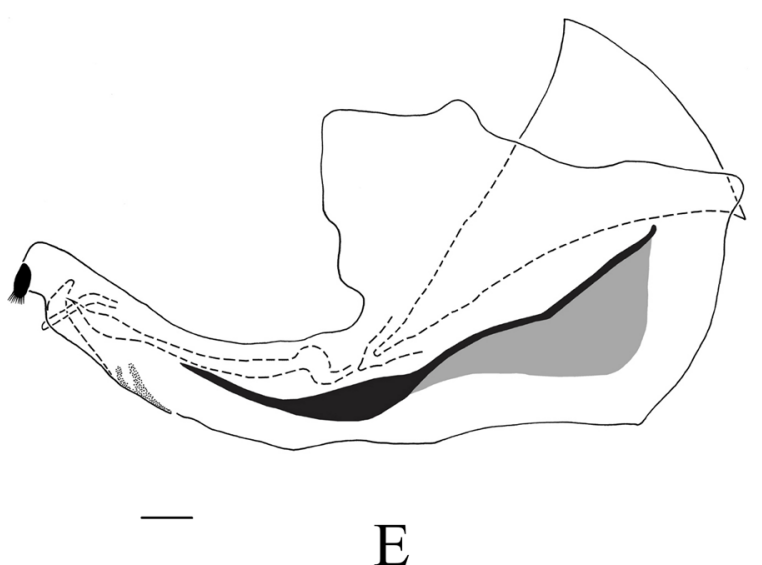

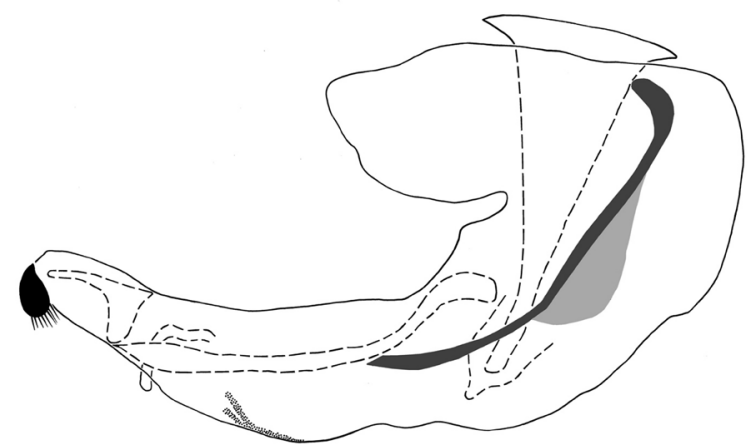

B

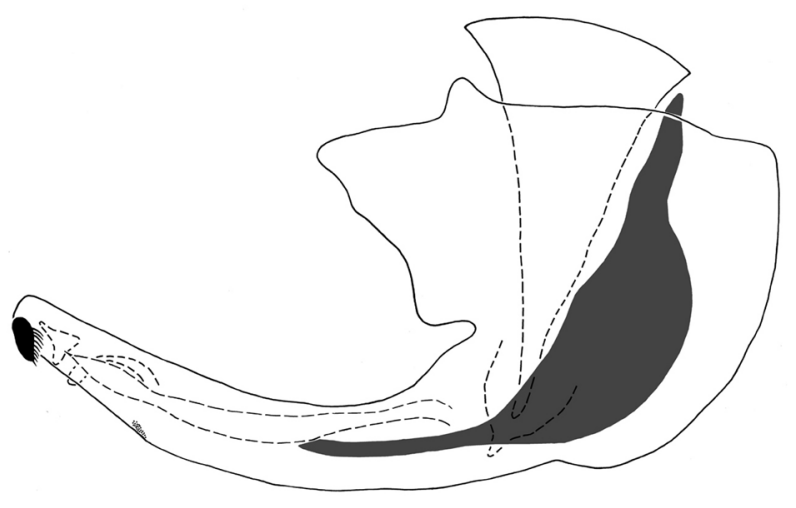

$\mathrm{D}$

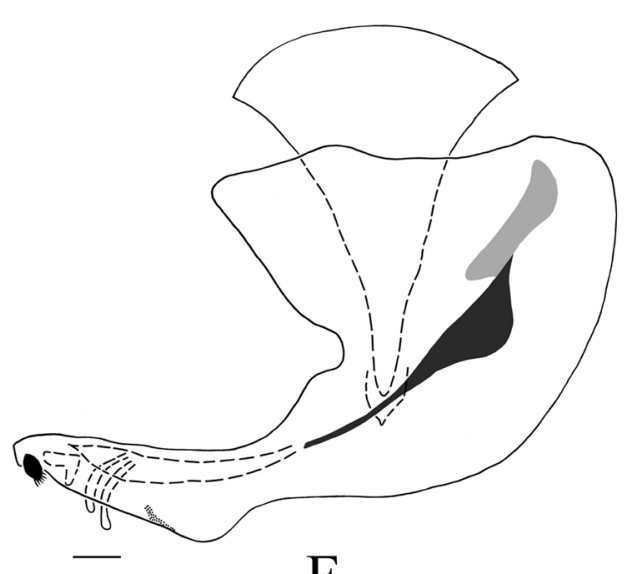

$\mathrm{F}$

Fig. 22. Hypandrium, lateral view. A. Eumerus atricolorus Gilasian \& van Steenis sp. nov., holotype (HMIM). B. E. brevipilosus Gilasian \& van Steenis sp. nov., holotype (HMIM). C. E. chekabicus Gilasian \& van Steenis sp. nov., holotype (HMIM). D. E. coeruleus (Becker, 1913), Chekab Valley, Iran (HMIM). E. E. ovoformus Gilasian \& van Steenis sp. nov., holotype (HMIM). F. E. richteri Stackelberg, 1960, Lar, Iran (HMIM). Scale bars $=0.1 \mathrm{~mm}$. 


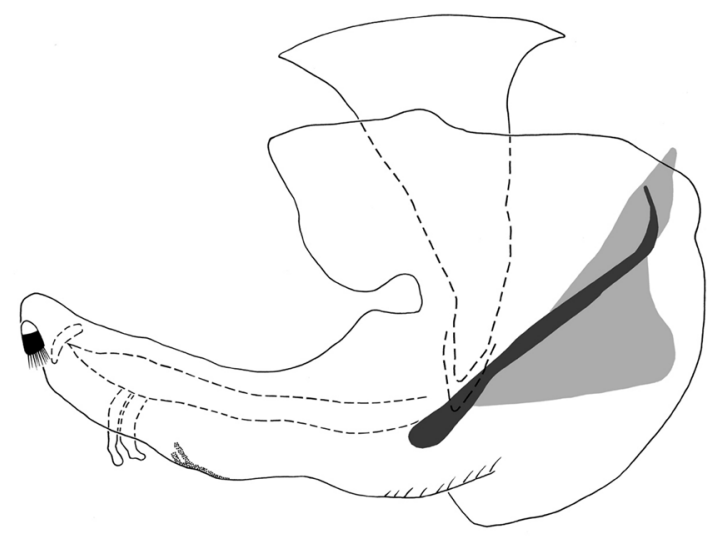

A

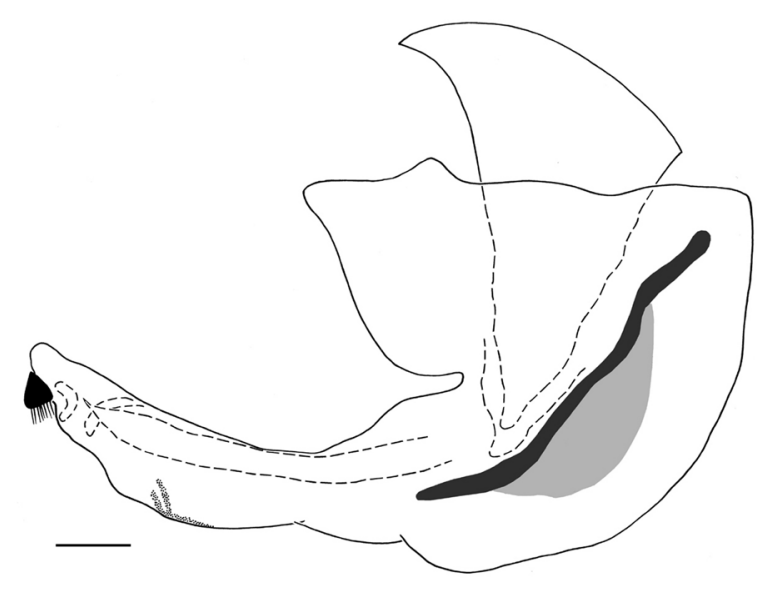

$\mathrm{C}$

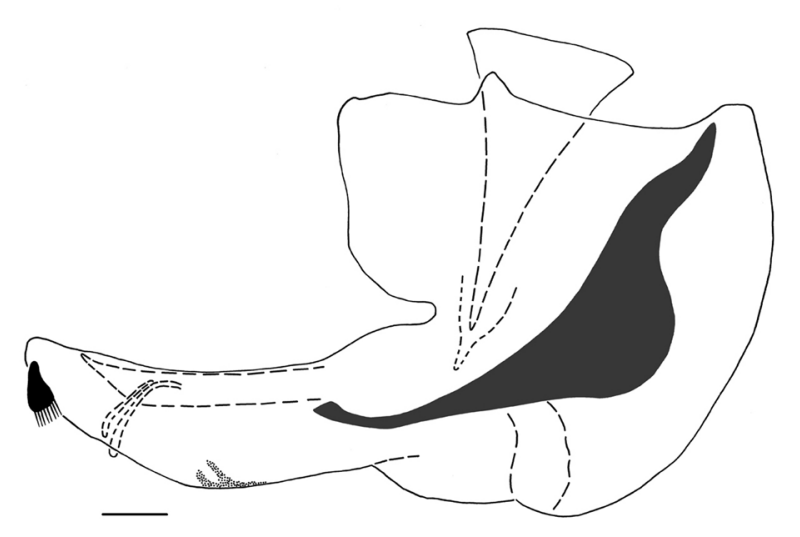

$\mathrm{B}$

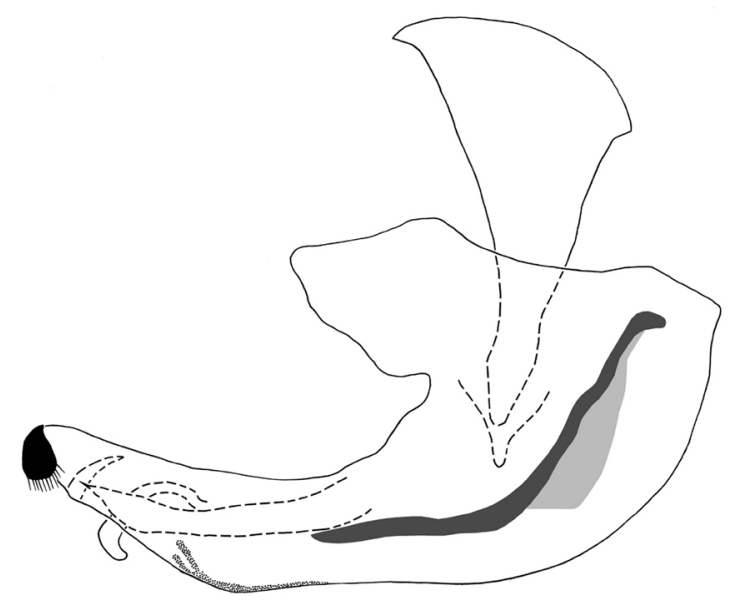

$\mathrm{D}$

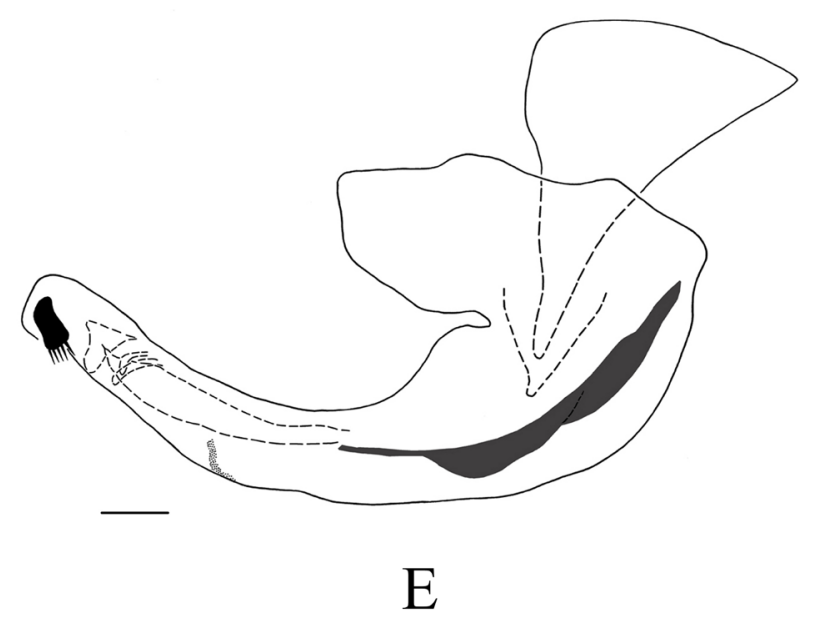

Fig. 23. Hypandrium, lateral view. A. Eumerus hissaricus Stackelberg, 1949, Ghoochan, Iran (HMIM). B. E. kazanovzkyae Paramonov, 1927, Paveh, Iran (HMIM). C. E. pilosipedes Gilasian \& van Steenis sp. nov., holotype (HMIM). D. E. vallicolus Gilasian \& van Steenis sp. nov., holotype (HMIM). E. Eumerus sp., Khash, Iran (HMIM). Scale bars $=0.1 \mathrm{~mm}$. 


\section{Diagnosis}

Eyes pilose (Fig. 13I); males dichoptic, distance between eyes less than width of ocellar triangle; basoflagellomere black; scutum and scutellum shiny metallic, weakly pollinose; scutum entirely and evenly pilose, pile on scutum very short (Fig. 8E), shorter than combined length of two basal segments of arsita; legs predominantly black; metafemur slightly enlarged; tibiae black except for narrow basal orange margin; wing hyaline, entirely covered with microtrichia; abdomen predominantly orange.

\section{Material examined}

IRAN • 1 đ̃; "IRAN, Kohkilouyeh \& / Boyerahmad prov., Yasuj / Tolegorgi, 2000 m, 4.v.1985/ H. Mirzayans \& A. Hashemi // Eumerus tricolor / (Fabricius, 1798)"; HMIM • 1 q; "Iran-Esfehan-Natanz / Bidhand / 3329'43.9"N, 051²5'39.0"E / 2349m. / 2009.V.18 / Leg. E. Gilasian"; JSA.

\section{Distribution}

Central Asia, Iran (Kohkilouyeh \& Boyerahmad prov., Yasuj; Esfehan prov.), Transcaucasia (Peck 1988; Barkalov \& Gharali 2004; Gilasian \& Barkalov 2004).

Eumerus vallicolus Gilasian \& van Steenis sp. nov. urn:lsid:zoobank.org:act:DB618219-7086-4DFA-82AC-F261D536B68D

Figs $4 \mathrm{H}, 7 \mathrm{H}, 10 \mathrm{D}, 11 \mathrm{I}, 12 \mathrm{~F}, 17 \mathrm{G}-\mathrm{H}, 19 \mathrm{D}, 21 \mathrm{D}, 23 \mathrm{D}$

\section{Diagnosis}

This species differs from the species E. tricolor, E. pamirorum, E. sarybulunis and E. coeruleithorax by the following characters: eyes distinctly dichoptic, 5-6 ommatidia spaced, distance between eyes wider than in E. tricolor but narrower than in E. pamirorum and E. coeruleithorax, eyes in E. sarybulunis coalescent over some distance; frontal triangle with dense whitish pile like in E. sarybulunis (it is not covered with so dense pile in E. tricolor, frontal triangle in E. coeruleithorax with sparse black pile and in E. pamirorum with sparse white pile); ocellar triangle narrow like in E. tricolor (it is wider in other species); ocellar triangle black pilose like in the European E. tricolor (with white pile in Turkish E. tricolor and other species); thorax with relatively long pile like in E. coeruleithorax (with very short pile in E. tricolor and covered with longer pile in E. sarybulunis and E. pamirorum); metafemur narrow like in E. tricolor (in other species it is either longer pilose and/or incrassate); abdominal maculae on terga III and IV more oblique than in other species.

\section{Etymology}

The name 'vallicolus' [Latin] is derived from 'vallis' (valley) and 'incola' (dweller), in reference to Chekab Valley, where the holotype was collected.

\section{Material examined}

Holotype

IRAN - J'; "IRAN: Markazi prov., Haftad / Qolleh Protected Area, / Chekab Valley, 2219 m, / $34^{\circ} 07^{\prime} 0.5^{\prime \prime} \mathrm{N}, 050^{\circ} 16^{\prime} 25.3^{\prime \prime} \mathrm{E}, / 28 . \mathrm{v}-15 . v i .2016$, Malaise trap / near pool, E. Gilasian \& M. / ParchamiAraghi // HOLOTYPUS § / Eumerus vallicolus / Gilasian \& van Steenis / 2020 [red label]"; HMIM.

\section{Description}

Male (Figs 4H, 7H)

MeAsuREMENTS. Body length: $6 \mathrm{~mm}$; wing length: $4.5 \mathrm{~mm}$. 
HEAD (Fig. 17G-H). Eyes short yellowish pilose, dichoptic, 5-6 ommatidia spaced; face nearly parallelsided, shiny black and covered with short yellowish-white pile; frontal triangle black, weakly pollinose and covered with dense whitish pile; head in frontal view 4.3 times as wide as face; frontal triangle 1.6 times as long as vertical triangle; vertical triangle shiny black, with brownish pile; ocellar triangle isosceles; ocellar triangle shiny black, with blackish pile, 1.1 times as long as wide and 1.4 times as long as vertical triangle; distance between posterior ocelli to posterior margin of eye about 0.6 times as long as ocellar triangle; occiput light grey pollinose, with yellowish pile; frontal triangle 1.25 times as wide as ocellar triangle; vertex at posterior corner of eyes 1.2 times as wide as vertex over posterior ocelli; head in dorsal view 5.3 times as wide as vertex at posterior corner of eyes; antennae brownish-black; basoflagellomere almost 0.9 times as long as wide; arista about 2 times as long as basoflagellomere (Fig. 11I).

THORAX. Scutum and scutellum shiny black, with relatively long white pile, without median pollinose vittae; posterolateral part of scutum with a longitudinal row of black seulae above base of wing; scutellum with marginal rim; pleurae shiny black; anepisternum, anepiemron and katepisternum with short whitish pile.

Legs (Fig. 10D). Predominantly black, short yellowish-brown pilose; apex of femora and basal narrow margin of tibiae orange; metafemur simple, narrow, about 4 times as long as wide; anteroventral and posteroventral margins of metafemur each with a row of 11 respectively 6 black setae in about apical half; metatarsus with tuft of dense orange pile ventrally.

WING. Hyaline, entirely microtrichose; vein $\mathrm{R}_{4+5}$ slightly sinuate; calypters yellowish; halter yellowishorange.

ABDOMEN. Tergum I black with short blackish pile; tergum II mostly orange except for anterior black margin and median black vitta not reaching posterior margin of segment; tergum II yellowish pile except for short blackish pilosity on its posterior third; tergum III entirely orange, mostly short blackish pile except for whitish pile on its white maculae; tergum IV black, with mostly short whitish pile except for short black pile on its anterior and posterior margin; sterna short yellowish pilose; sternum I black in anterior half and orange in posterior half; sterna II and III orange; sternum IV black, rectangular, with rounded posterolateral corners and with median wide V-shaped incision posteriorly (Fig. 12F).

Genitalia (Figs 19D, 21D, 23D). Hypandrium simple; aedeagal apodeme relatively narrow in lateral view; posterior lobe of surstylus in lateral view sharply extending outward posteroventrally, with a longitudinal row of short and black setulae posteriorly, with a few short median setulae and with 2-3 setae anteriorly, posterior lobe of surstylus in dorsal view uniformly rounded apically, almost balloonshaped, covered with short setulae; inner accessory lobe of surstylus with short pile.

Female

Unknown.

\section{Distribution}

Iran.

\section{Identification key to the males of the Eumerus tricolor species group in Iran}

Females are not included in the following key because they are either unknown for most of the species or morphologically difficult to separate from each other. 
1. Basoflagellomere radially furrowed, apicolaterally with clearly demarcated, ellipsoidal fossa (Fig. 11A-I); katepisternum almost entirely pilose; wing vein costa with a row of long posterodorsal setae basally (Fig. 8F); terga often more or less red coloured; anterior surstylus lobe undeveloped (Figs 18A-F, 19A-E) tricolor group 2

- Basoflagellomere without radial grooves, its fossa unclear; katepisternum with separate dorsal and ventral pile patch; wing vein costa with at most short posterodorsal pile basally; terga black coloured, in some species with yellow transparent maculae on tergum II laterally; anterior surstylus lobe more or less developed other Eumerus groups

2. Eyes pilose (as in Fig. 15A); scutum and scutellum shiny metallic, weakly pollinose (as in Fig. 3C); legs predominantly black; metafemur slightly enlarged (as in Fig. 9A)

- Eyes bare (Fig. 15C-D); scutum and scutellum strongly pollinose, with very short yellowish pile and with 4 longitudinal blackish vittae (Fig. 3F); legs predominantly orange (Fig. 6F); metafemur strongly enlarged

E. jacobsoni Becker, 1913

3. Metaleg extremely long and slender (Fig. $7 \mathrm{G}$ )

- Metaleg not elongated, clearly enlarged (especially metafemur)

4. Eyes widely spaced (Fig. 17E); face white pilose; scutum brownish pilose, without pollinose vittae; wing infuscated (Fig. 4G); abdominal terga II-IV predominantly reddishorange

E. tadzhikorum Stackelberg, 1949

- Eyes only about 1 ommatidium spaced (Fig. 15G); face black pilose, in some specimens entirely white pilose; scutum white pilose, with 2 narrow median pollinose vittae; wing hyaline (Fig. $3 \mathrm{H}$ ); abdomen black

E. longitarsis Peck, 1979

5. Wing extensively bare of microtrichia, also on apical half; protarsus with strong setae along posterior margin, especially basitarsomere with several setae along entire posterior margin; subscutellar pile fringe long and dense and with apices strongly bent medially; pleura above metacoxa pilose

E. persarum Stackelberg, 1961

- Wing almost entirely covered with microtrichia, basal cells sometimes partly bare; protarsus without strong setae along posterior margin, or at most with one apical seta on each tarsomere; subscutellar pile fringe long or short, not dense, and with apices at most very slightly bent medially; pleura above metacoxa bare

6. Wing at least slightly infuscated; metatarsus with dense thick black pile fringe …........................ 7

- Wing hyaline; metatarsus without dense thick black pile fringe .................................................... 8

7. Eyes 3-4 ommatidia spaced (Fig. 17A); scutum and pleurae with relatively long pile; metafemur with long ventral pile, about $1 / 4-1 / 3$ width of metafemur; dense dorsal thick pile fringe on metatibia almost absent (Fig. 10B); metatarsus with pile fringe on entire dorsal surface (Fig. 10C); wing slightly infuscated in apical half from anterior margin to anterior half of cell $\mathrm{dm}$; male genitalia as in Figs 19C, 21C, 23C

E. pilosipedes Gilasian \& van Steenis sp. nov.

- Eyes about 1 ommatidium spaced (Fig. 15E); scutum and pleurae with short pile; metafemur with short ventral pile, about $1 / 8-1 / 7$ width of metafemur; metatibia with dense dorsal thick pile fringe apically (Fig. 10A); metatarsus pile fringe confined to antero-dorsal margin of metatarsus; wing strongly infuscated reaching to posterior margin of wing; male genitalia as in Figs 19B, 21B, 23B

E. kazanovzkyae Paramonov, 1927

8. Eyes holoptic with long eye contiguity 9

- Eyes dichoptic, in some species coalescent in one point 10 
9. Eye contiguity about 0.7 times as long as frontal triangle; face and frontal triangle white pilose (Fig. 13H); scutum with long yellowish pile (Fig. 6D); abdomen predominantly reddish-orange (Fig. 3D); male genitalia as in Figs 18C, 20C, 22C

E. chekabicus Gilasian \& van Steenis sp. nov.

- Eye contiguity about 0.4 times as long as frontal triangle; face and frontal triangle black pilose (Fig. 16C-D); scutum with mix of white and black pile (Fig. 7B); abdomen brownish-black (Fig. 4B); male genitalia as in Figs 19A, 21A, 23A E. hissaricus Stackelberg, 1949

10. Eyes widely spaced, distance between eyes more than width of ocellar triangle (Fig. 13E); scutum pilose, with two bare longitudinal areas posteromedially; scutellum, in lateral view, strongly arched basally, more than half as high as long

E. falsus Becker, 1922

- Eyes less widely spaced, distance between eyes less than width of ocellar triangle; scutum entirely and evenly pilose; scutellum more flat, at most $1 / 4$ as high as long

11. Pile on scutum at least equal to combined length of two basal segments of arista ....................... 12

- Pile on scutum very short, shorter than combined length of two basal segments of arista ............ 16

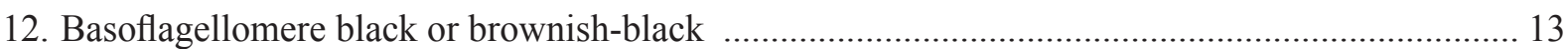

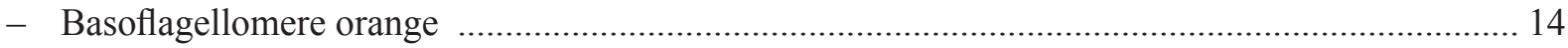

13. Eyes 6-7 ommatidia spaced (Fig. 17G); tergum III entirely and tergum II mostly orange; male genitalia as in Figs 19D, 21D, 23D; body length: $6 \mathrm{~mm}$

E. vallicolus Gilasian \& van Steenis sp. nov.

- Eyes coalescent in one point (Fig. 13A); terga almost entirely reddish-brown (Fig. 3A); male genitalia as in Figs 18A, 20A, 22A; body length: $9.7 \mathrm{~mm}$.......E. atricolorus Gilasian \& van Steenis sp. nov.

14. Eyes distinctly dichoptic; scutum and scutellum with dense pile; legs long pilose; abdomen mostly orange 15

- Eyes coalescent in one point (Fig. 17C); scutum and scutellum with less dense pile; legs short pilose; abdomen brownish-black; male genitalia as in Figs 18F, 20F, 22F ......E. richteri Stackelberg, 1960

15. Basoflagellomere egg-shaped (Fig. 11G); eyes 8-9 ommatidia spaced (Fig. 16E); ocellar triangle isosceles; vein $\mathrm{R}_{4+5}$ slightly sinuate; legs predominantly black except for orange apex of femora and orange basal third of tibiae; abdominal tergum III almost entirely orange; male genitalia as in Figs 18E, 20E, 22E

E. ovoformus Gilasian \& van Steenis sp. nov.

- Basoflagellomere not egg-shaped; eyes about 4 ommatidia spaced (Fig. 15A); ocellar triangle equilateral; vein $\mathrm{R}_{4+5}$ deeply sinuate; tarsi and basal half of tibiae orange; abdominal tergum III with distinct median black vitta; male genitalia as in Figs 18D, 20D, 22D ....E. coeruleus (Becker, 1913)

16. Basoflagellomere orange (Fig. 11B); frontal triangle with dense pile; tibiae orange in basal third; abdomen black (Fig. 3B); male genitalia as in Figs 18B, 20B, 22B

E. brevipilosus Gilasian \& van Steenis sp. nov.

- Basoflagellomere black; frontal triangle with less dense pile (Fig. 13I); tibiae predominantly black except for narrow basal orange margin; abdomen predominantly orange; male genitalia as in Grković et al. (2017: 188, fig. 11d)

E. tricolor (Fabricius, 1798)

\section{Discussion}

Prior to this study, the Iranian Eumerus tricolor group was represented by only eight species mostly recorded from the southeastern Balouchestan region, four of which had originally been described from 
Iran, i.e., Eumerus coeruleus, E. jacobsoni, E. persarum and E. persicus (Stackelberg 1961; Peck 1988; Barkalov \& Gharali 2004; Gilasian \& Barkalov 2004; Kamangar et al. 2004; Bahirai et al. 2014).

The species Eumerus zarudnyi Stackelberg, 1949, which was described from western Iran, is considered as a synonym of $E$. falsus by Peck (1988). In their catalogue of the Iranian Syrphidae, Dousti \& Hayat (2006) erroneously added E. lunatus (Fabricius, 1794) by referring to Barkalov \& Gharali (2004), who only reported the species E. tricolor and E. tadzhikorum of the tricolor species group for Iran.

Based on available data on the distribution of the Eumerus tricolor group in Iran, we conclude that the Haftad Qolleh Protected Area (Fig. 1), with eight known species out of a total of 17 Iranian species, holds the most diverse fauna of the group throughout the country. This area, which covers an estimated 97000 hectares and contains two major valleys, Chekab and Sibak, is located to the east of the provincial capital city of Arak. This mountainous area, with a height of about $3000 \mathrm{~m}$ a.s.l. at its summit, has $350 \mathrm{~mm}$ of annual precipitation and its temperature varies from $-30^{\circ} \mathrm{C}$ to $38^{\circ} \mathrm{C}$ during the year. Natural springs provide needed water for the wild animals during the dry season. Haftad Qolleh serves as a biodiversity hotspot whose flora comprises at least 641 plant species from 63 families, of which the family Asteraceae with 105 recorded species is the dominant family (Ansari 2017).

Despite that a few species of this group are widely distributed in the West Palaearctic region such as Eumerus tricolor, the available distribution data show that most of the group's species occur in Transcaucasia, Central Asia and the semi-arid to arid areas of Iran. Therefore, we believe that the Eumerus tricolor group fauna in these areas comprises distinctively different species from those of the European and northern African fauna (Peck 1988; Grković et al. 2017, 2019a).

A meticulous examination of the wing vein costa, resulted the observation of a posterodorsal row of long black or light setae basally which extends at least to its half length to crossvein $\mathrm{r}-\mathrm{m}$. This character, which appears in all examined Eumerus tricolor group specimens, is here presented for the first time and is included in the diagnosis for this species group.

A male specimen (Figs 4A, 7A, 19E, 21E, 23E), collected by Malaise trap from the southeastern city of Khash (Fig. 2), shows striking differences to all other Iranian species in the following combined morphological characters: eyes pilose and dichoptic; face and frons white pilose; ocellar triangle isosceles; basoflagellomere orange; scutum covered with short yellowish pile and with two narrow median pollinose vittae; wing entirely microtrichose; legs predominantly black; protarsus without strong setae posteriorly; abdomen brownish-black. Although it is superficially similar to Eumerus mesasiaticus, it is readily separated from this species by its entirely microtrichose wing, lacking strong setae on the protarsus posteriorly, bare metakatepisternum and simple metafemur (without hump basoventrally). At this point, we have decided to leave this specimen as Eumerus sp. until further sampling from the same locality and relevant type examinations provide sufficient data to determine its identity.

\section{Acknowledgments}

Our special thanks go to the Iranian Department of Environment and Iranian Research Institute of Plant Protection (IRIPP) for funding this research. We thank Olga Ovchinnikova and Nikolai Paramonov (St. Petersburg, Russia), Andrey Ozerov, Marina Krivosheina and Anatoly Shatalkin (Moscow, Russia) and Jenny Pohl (Berlin, Germany) for the possibility of studying material in their care. We also thank Dr Martin Hauser (California, USA) for sharing his data bank of world Eumerus and sending us old literature of the genus. The second author is grateful to the Dutch Uyttenboogaart-Eliasen foundation for its financial support under numbers SUB.2014.12.16 and SUB.2019.05.21 to visit the St. Petersburg and Moscow museums respectively. 


\section{References}

Achterberg C. van. 2009. Can Townes type Malaise traps be improved? Some recent developments. Entomologische Berichten 69 (4): 129-135.

Ansari A. 2017. Habitat evaluation for Persian Gazelle in the Southern half of Markazi province, Iran. Journal of Wildlife and Biodiversity 1 (1): 19-23. https://doi.org/10.22120/jwb.2017.27137

Bahirai F., Mehrvar A., Gharali B., Lotfalizadeh H.A. \& Jafari S. 2014. Diversity of flower flies (Dip.: Syrphidae) in Lorestan province. Journal of Entomological Research 7 (1): 1-15.

Barkalov A. \& Gharali B. 2004. Description of a new species of the genus Eumerus (Dip.: Syrphidae) from Iran. Volucella 7: 105-109.

Becker T. 1913. Persische Dipteren von den Expeditionen des Herrn N. Zarudny 1898 und 1901. Annuaire du Musée zoologique de l'Académie des sciences de St. Pétersbourg 17 (1912): 503-654. https://doi.org/10.5962/bhl.title.8570

Becker T. 1921. Neue Dipteren meiner Sammlung. Mitteilungen aus dem Zoologischen Museum in Berlin 10: 1-93.

Doczkal D. 1996. Description of two new species of the genus Eumerus Meigen (Diptera, Syrphidae) from Corsica. Volucella 2: 3-19.

Dousti A.F. \& Hayat R. 2006. A catalogue of the Syrphidae (Insecta: Diptera) of Iran. Journal of Entomological Research Society 8 (3): 5-38.

Fabricius J.C. 1798. Supplementum Entomologiae Systematicae. Proft et Storch, Copenhagen [= Hafniae]. https://doi.org/10.5962/bhl.title.122153

Gilasian E. \& Barkalov A. 2004. Introduction of two species of Eumerus (Dip.: Syrphidae) from Iran. Proceeding of the $16^{\text {th }}$ Iranian Plant Protection Congress 1: 130.

Goot V.S. van der. 1964. Fluke's catalogue of Neotropical Syrphidae (Insects, Diptera), a critical study with an appendix on new names in Syrphidae. Beaufortia 10: 212-221. Available from https://repository.naturalis.nl/pub/505099 [accessed 26 Oct. 2020].

Grković A., Vujić A., Radenković S., Chroni A. \& Petanidou T. 2015. Diversity of the genus Eumerus Meigen (Diptera, Syrphidae) on the eastern Mediterranean islands with description of three new species. Annales de la Société entomologique de France 51 (4): 361-373.

https://doi.org/10.1080/00379271.2016.1144483

Grković A., Vujić A., Chroni A., Steenis J. van, Đan M. \& Radenković S. 2017. Taxonomy and systematics of three species of the genus Eumerus Meigen, 1822 (Diptera: Syrphidae) new to southeastern Europe. Zoologischer Anzeiger 270: 176-192. https://doi.org/10.1016/j.jcz.2017.10.007

Grković A., Smit J., Radenković S., Vujić A. \& Steenis J. van. 2019a. Two new European long-legged hoverfly species of the Eumerus binominatus species subgroup (Diptera, Syrphidae). ZooKeys 858: 91-108. https://doi.org/10.3897/zookeys.858.34663

Grković A., Steenis J. van, Kočiš Tubić N., Nedeljković Z., Hauser M., Hayat R., Demırözer O., Đan M., Vujić A. \& Radenković S. 2019b. Revision of the bactrianus subgroup of the genus Eumerus Meigen (Diptera: Syrphidae) in Europe, inferred from morphological and molecular data with descriptions of three new species. Arthropod Systematics and Phylogeny 77 (1): 21-37.

https://doi.org/10.26049/ASP77-1-2019-02

Kamangar S., Mansour Ghazi M. \& Gharali B. 2004. Identification of syrphid flies in wheat fields, and a survey on population fluctuations of the dominant species in Kurdistan province. Proceeding of the $16^{\text {th }}$ Iranian Plant Protection Congress 1: 144. 
Mutin V.A. 2016. Species of the genus Eumerus Meigen, 1822 (Diptera: Syrphidae) from the Northern Minusinsk hollow, Republic of Khakassia. Euroasian Entomological Journal 1: 103-107.

Mutin V.A. 2019. A new species of the genus Eumerus Meigen, 1822 (Diptera: Syrphidae) from Turkmenistan. Far Eastern Entomologist 397: 9-12. https://doi.org/10.25221/fee.397.2

Peck L.V. 1966. New and little known hover-flies (Diptera, Syrphidae) from Kirghizia. Entomologicheskoe Obozrenie 45: 188-196.

Peck L.V. 1971. A description of new and little known flies of the genera Cheilosia, Eristalis and Eumerus (Diptera, Syrphidae) from Kirghiza. Entomologicheskoe Obozrenie 50: 695-705.

Peck L.V. 1988. Family Syrphidae. In: Soós Á. \& Papp L. (eds) Catalogue of Palaearctic Diptera. Syrphidae-Conopidae. Volume 8: 11-230. Akadémiai Kiadó, Budapest.

Ricarte A., Marcos-García M.Á. \& Rotheray G.E. 2008. The early stages and life histories of three Eumerus and two Merodon species (Diptera: Syrphidae) from the Mediterranean region. Entomologica Fennica 19: 129-141. https://doi.org/10.33338/ef.84424

Ricarte A., Souba-Dols G.J., Hauser M. \& Marcos-García M.Á. 2017. A review of the early stages and host plants of the genera Eumerus and Merodon (Diptera: Syrphidae), with new data on four species. PLoS ONE 12 (12): e0189852. https://doi.org/10.1371/journal.pone.0189852

Ricarte A., Nencioni A., Kočiš Tubić N., Grković A., Vujić A. \& Marcos-García M.Á. 2018. The hoverflies of an oak Dehesa from Spain, with a new species and other insights into the taxonomy of the Eumerus tricolor group (Diptera: Syrphidae). Annales Zoologici 68 (2): 259-280.

https://doi.org/10.3161/00034541ANZ2018.68.2.005

Sack P. 1932. Syrphidae. In: Lindner E. (ed.) Die Fliegen der Palaearktischen Region IV/6: 1-451. Schweizerbart, Stuttgart.

Souba-Dols G.J., Ricarte A., Hauser M., Speight M. \& Marcos-García M.Á. 2020. What do Eumerus Meigen larvae feed on? New immature stages of three species (Diptera: Syrphidae) breeding in different plants. Organisms Diversity \& Evolution 20 (2): 267-284. https://doi.org/10.1007/s13127-020-00437-0

Stackelberg A.A. 1949. New data on the genus Eumerus Mg. (Diptera, Syrphidae) of the Palaearctic fauna. Entomologicheskoe Obozrenie 30 (3-4): 426-439.

Stackelberg A.A. 1961. Palaearctic species of the genus Eumerus Mg. (Diptera, Syrphidae). Trudy Vsesoyuznogo Entomologicheskogo Obshchestva 48: 18-229.

Steenis J. van \& Wyatt N.P. 2020. The first species of Trichopsomyia Williston, 1888 (Diptera: Syrphidae) described from the Oriental region, with a discussion on the character states of the pilosity of the katepisternum. European Journal of Taxonomy 687: 1-12. https://doi.org/10.5852/ejt.2020.687

Steenis J. van, Hauser M., Zuijen M.P. van. 2017. Review of the Eumerus barbarus species group (Diptera: Syrphidae) from the western Mediterranean Basin. Bonn Zoological Bulletin 66 (2): 145-165.

Thompson F.C. 1999. A key to the genera of the flower flies (Diptera: Syrphidae) of the Neotropical Region including redescriptions of new genera and species and a glossary of taxonomic terms. Contributions on Entomology, International 3: 320-378. Available from https://repository.si.edu/handle/10088/17492 [accessed 7 Oct. 2020].

Manuscript received: 9 May 2020

Manuscript accepted: 27 August 2020

Published on: 2 November 2020 
Topic editor: Nesrine Akkari

Desk editor: Pepe Fernández

Printed versions of all papers are also deposited in the libraries of the institutes that are members of the EJT consortium: Muséum national d'histoire naturelle, Paris, France; Meise Botanic Garden, Belgium; Royal Museum for Central Africa, Tervuren, Belgium; Royal Belgian Institute of Natural Sciences, Brussels, Belgium; Natural History Museum of Denmark, Copenhagen, Denmark; Naturalis Biodiversity Center, Leiden, the Netherlands; Museo Nacional de Ciencias Naturales-CSIC, Madrid, Spain; Real Jardín Botánico de Madrid CSIC, Spain; Zoological Research Museum Alexander Koenig, Bonn, Germany; National Museum, Prague, Czech Republic. 